To appear in Philosophical Studies

DOI: 10.1007/s11098-013-0161-3

Visit http://link.springer.com/journal/11098 for official version

\title{
Confirmation, Transitivity, and Moore: The Screening-Off Approach
}

William Roche* and Tomoji Shogenji†

* Department of Philosophy, Texas Christian University, Fort Worth, TX, USA, e-mail:

w.roche@tcu.edu

$\dagger$ Department of Philosophy, Rhode Island College, Providence, RI, USA, e-mail:

tshogenji@ric.edu

ABSTRACT: It is well known that the probabilistic relation of confirmation is not transitive in that even if E confirms $\mathrm{H} 1$ and $\mathrm{H} 1$ confirms H2, E may not confirm H2. In this paper we distinguish four senses of confirmation and examine additional conditions under which confirmation in different senses becomes transitive. We conduct this examination both in the general case where $\mathrm{H} 1$ confirms $\mathrm{H} 2$ and in the special case where $\mathrm{H} 1$ also logically entails $\mathrm{H} 2$. Based on these analyses, we argue that the Screening-Off Condition is the most important condition for transitivity in confirmation because of its generality and ease of application. We illustrate our point with the example of Moore's "proof" of the existence of a material world, where H1 logically entails H2, the Screening-Off Condition holds, and confirmation in all four senses turns out to be transitive.

KEYWORDS: Confirmation; Transitivity; Transmission; Increase in Firmness; Sufficient Firmness; Turning Sufficiently Firm; the Screening-Off Condition; the Dragging Condition; the Addition Condition; Moore's Proof; the Converse Consequence Condition.

\section{Introduction}

In most cases where evidence supports a hypothesis, their relation is not that of logical entailment but probabilistic confirmation. The evidence makes the hypothesis "firm" but not in the sense of absolute certainty - the evidence makes it "firm" only in the sense of making it more probable or 
making it sufficiently probable. ${ }^{1}$ We will call probabilistic confirmation of the first kind "confirmation-IF" (IF for Increase in Firmness) and probabilistic confirmation of the second kind "confirmation-SF" (SF for Sufficient Firmness). To express these relations formally, evidence E confirms-IF hypothesis $\mathrm{H}$ iff $\operatorname{Pr}(\mathrm{H} \mid \mathrm{E})>\operatorname{Pr}(\mathrm{H})$; evidence $\mathrm{E}$ confirms-SF hypothesis $\mathrm{H}$ iff $\operatorname{Pr}(\mathrm{H} \mid \mathrm{E})$ $>\mathbf{t}$, where $\mathbf{t}$ is the threshold for rational acceptability (or justification or warrant) and $.5 \leq \mathbf{t}<1 .{ }^{2}$ Although both kinds of probabilistic confirmation are widely recognized, calling confirmation-SF "confirmation" is somewhat misleading because E may confirm-SF $\mathrm{H}$ in the formal sense of $\operatorname{Pr}(\mathrm{H} \mid$ E) $>\mathbf{t}$ while E actually makes $\mathrm{H}$ less firm in the sense of $\operatorname{Pr}(\mathrm{H} \mid \mathrm{E})<\operatorname{Pr}(\mathrm{H})$. We can eliminate such counterintuitive cases by regarding sufficient firmness as a condition added to confirmation-IF. In other words, E "confirms" $\mathrm{H}$ in the third sense iff E both confirms-IF H and confirms-SF H. We will call it "confirmation-IF\&SF". Some may object that even confirmation-IF\&SF is not really confirmation in the sense of "making $\mathrm{H}$ sufficiently firm". In hearing "E makes $\mathrm{H}$ sufficiently firm", we naturally think that $\mathrm{E}$ turns $\mathrm{H}$ sufficiently firm. In other words, $\mathrm{H}$ is not sufficiently firm in the absence of $\mathrm{E}$. To capture this tacit implication, we may introduce confirmation-TSF (TSF for Turning Sufficiently Firm) as the fourth sense of "confirmation". To express it formally, E confirms-TSF $\mathrm{H}$ iff $\operatorname{Pr}(\mathrm{H} \mid \mathrm{E})>\mathbf{t}$ and $\operatorname{Pr}(\mathrm{H}) \leq \mathbf{t}$. If E confirms-TSF $\mathrm{H}$, then E confirms-IF\&SF $H$, but $\mathrm{E}$ can confirm-IF\&SF $\mathrm{H}$ and yet not confirm-TSF $\mathrm{H}$.

Once we broaden our attention beyond deductive relations and turn to the probabilistic relation of confirmation, we lose one important feature in epistemic reasoning-viz. transitivity of epistemic support. The deductive relation of entailment is transitive: For any E, H1 and H2, if E entails $\mathrm{H} 1$ and $\mathrm{H} 1$ in turn entails $\mathrm{H} 2$, then E entails $\mathrm{H} 2$. In contrast, the probabilistic relation of confirmation is not transitive: It is possible that $\mathrm{E}$ confirms $\mathrm{H} 1, \mathrm{H} 1$ confirms $\mathrm{H} 2$, yet $\mathrm{E}$ does not confirm H2. This is true of all four senses of confirmation distinguished above, and it is not difficult to construct a distribution of probabilities-for each sense of "confirmation"- such that E confirms $\mathrm{H} 1, \mathrm{H} 1$ confirms $\mathrm{H} 2$, yet $\mathrm{E}$ does not confirm $\mathrm{H} 2$. We can also see failure of transitivity in an informal description of a case. For example, someone's being an academic philosopher confirms-IF (increases the probability) that she has a doctoral degree, and someone's having a doctoral degree confirms-IF (increases the probability) that she is well paid. It does not follow, unfortunately, that someone's being an academic philosopher confirms-IF (increases the probability) that she is well paid. ${ }^{4}$

The distinction is clear-cut so far: The deductive relation of entailment is transitive, while the probabilistic relation of confirmation is not transitive. The situation becomes complicated in

\footnotetext{
${ }^{1}$ Cf. Carnap (1962, Preface to the Second Edition) on "concepts of increase in firmness" and "concepts of firmness".

${ }^{2}$ We leave it open that $\mathbf{t}$ may be context-dependent (perhaps higher in higher-stakes contexts and lower in lower-stakes contexts). We are following the standard view here that whether $\mathrm{H}$ is rationally acceptable given $\mathrm{E}$ is determined solely by $\operatorname{Pr}(\mathrm{H} \mid \mathrm{E})$ (and perhaps the context), though the view is not unproblematic. Cf. Shogenji (2012).

${ }^{3}$ Cf. Douven (2011, pp. 487-488) on "t-evidence", and Chandler (2010, p. 337) on "sufficient evidence".

${ }^{4}$ The example is taken from Shogenji (2003).
} 
special cases where in addition to E confirming $\mathrm{H} 1$ and $\mathrm{H} 1$ in turn confirming $\mathrm{H} 2$, $\mathrm{H} 1$ entails $\mathrm{H} 2$. The complication is that under the special condition of $\mathrm{H} 1 \mid-\mathrm{H} 2$ (H1 entails $\mathrm{H} 2$ ), confirmationSF is transitive but confirmation in the other three senses - confirmation-IF, confirmation-IF\&SF, and confirmation-TSF - is not. It is easy to see why confirmation-SF is transitive in the special case. The condition $\mathrm{H} 1 \mid-\mathrm{H} 2$ of the special case ensures that $\operatorname{Pr}(\mathrm{H} 2 \mid \mathrm{E}) \geq \operatorname{Pr}(\mathrm{H} 1 \mid \mathrm{E})$, while $\operatorname{Pr}(\mathrm{H} 1 \mid \mathrm{E})>\mathbf{t}$ from the antecedent of transitivity in confirmation-SF. It follows immediately that $\operatorname{Pr}(\mathrm{H} 2 \mid \mathrm{E})>\mathbf{t}$. Meanwhile, we can see that confirmation in the other three senses is not transitive even under the special condition in cases of "transmission failure" (at least some of them). Suppose Smith is visiting the local zoo, and let E be the claim "It appears to me (Smith) visually as if the animal in the pen before me is a zebra", $\mathrm{H} 1$ be the claim "The animal in the pen before me (Smith) is a zebra", and H2 be the claim "It is not the case that the animal in the pen before me (Smith) is a mule cleverly disguised to look like a zebra". ${ }^{5}$ E confirms-IF H1 (at least on certain ways of filling in the details), and H1 confirms-IF and entails H2. But E does not confirm-IF H2. Indeed, given that $\operatorname{Pr}(\mathrm{E})<1, \operatorname{Pr}(\neg \mathrm{H} 2)>0$, and $\neg \mathrm{H} 2$ entails $\mathrm{E}$ (again at least on certain ways of filling in the details), it follows that E confirms-IF $\neg \mathrm{H} 2$ and thus disconfirms-IF H2. ${ }^{6}$ Next, we suppose further, as seems plausible, that $\operatorname{Pr}(\mathrm{H} 1 \mid \mathrm{E})>\mathbf{t}$, so E confirms-SF H1 and $\mathrm{H} 1$ confirms-SF and entails H2. Then, as it is a theorem of the probability calculus that $\operatorname{Pr}(\mathrm{H} 2 \mid \mathrm{E}) \geq \operatorname{Pr}(\mathrm{H} 1 \mid \mathrm{E})$ provided $\mathrm{H} 1$ entails $\mathrm{H} 2$, it follows that $\mathrm{E}$ confirms-SF H2. It also follows, however, since confirmation-IF is required for confirmation-IF\&SF, that though E confirms-IF\&SF H1, and H1 confirms-IF\&SF and entails H2, it is not the case that E confirms-IF\&SF H2. Finally, we suppose even further, as seems arguable at least, that $\operatorname{Pr}(\mathrm{H} 2) \leq \mathbf{t}$. It follows that E confirms-TSF H1, and $\mathrm{H} 1$ confirms-TSF and entails H2, but given that confirmation-IF is required for confirmation-TSF, it is not the case that E confirms-TSF H2. Note that we retain the second antecedent of transitivity- $\mathrm{H} 1$ confirms $\mathrm{H} 2-$ which is not mentioned in the standard formulation of transmission failure. It is usually not mentioned because except for the uninteresting cases where $\mathrm{P}(\mathrm{H} 2)=0$ or $\mathrm{P}(\mathrm{H} 2)=1$, it follows from the special condition $\mathrm{H} 1 \mid-\mathrm{H} 2$, along with the condition $\operatorname{Pr}(\mathrm{H} 2) \leq \mathbf{t}$, that $\mathrm{H} 1$ confirms $\mathrm{H} 2$ in the sense of confirmation-IF, confirmation-IF\&SF, and confirmation-TSF. We do set aside those uninteresting cases, but retain the second antecedent of transitivity to underscore the point that transmission failure is a special case of non-transitivity.

To summarize, confirmation in all four senses - confirmation-IF, confirmation-SF, confirmation-IF\&SF, and confirmation-TSF-is non-transitive in the absence of additional conditions. Under the special condition that $\mathrm{H} 1$ entails $\mathrm{H} 2$, confirmation-SF is transitive, but confirmation in the other three senses is still non-transitive. Of course, non-transitive does not mean anti-transitive. It would be nice if there were some conditions under which confirmation-IF, confirmation-SF, confirmation-IF\&SF, or confirmation-TSF is transitive in the general case, or

${ }^{5}$ This case is adapted from Dretske (1970, pp. 1015-1016).

${ }^{6}$ This sort of point is made in Chandler (2010, p. 337), Cohen (2005, pp. 424-425), Hawthorne (2004, pp. 73-75), Okasha (1999, sec. 9), Silins (2005, p. 85, 2007, pp. 123-125), and White (2006, sec. 5). 
some conditions under which confirmation-IF, confirmation-IF\&SF, or confirmation-TSF is transitive in the special case where $\mathrm{H} 1$ entails $\mathrm{H} 2 .^{7}$

It turns out, fortunately, that there are such conditions for transitivity at least with respect to confirmation-IF. It has been shown in the general case that confirmation-IF is transitive under the condition $(\mathrm{C} 1):^{8}$

$$
\operatorname{Pr}(\mathrm{H} 2 \mid \mathrm{E} \wedge \mathrm{H} 1) \geq \operatorname{Pr}(\mathrm{H} 2 \mid \mathrm{H} 1) \text { and } \operatorname{Pr}(\mathrm{H} 2 \mid \mathrm{E} \wedge \neg \mathrm{H} 1) \geq \operatorname{Pr}(\mathrm{H} 2 \mid \neg \mathrm{H} 1) .
$$

(C1) is similar to, but weaker than, the condition that $\mathrm{H} 1$ "screens-off" $\mathrm{E}$ from $\mathrm{H} 2$ :

$$
\operatorname{Pr}(\mathrm{H} 2 \mid \mathrm{E} \wedge \mathrm{H} 1)=\operatorname{Pr}(\mathrm{H} 2 \mid \mathrm{H} 1) \text { and } \operatorname{Pr}(\mathrm{H} 2 \mid \mathrm{E} \wedge \neg \mathrm{H} 1)=\operatorname{Pr}(\mathrm{H} 2 \mid \neg \mathrm{H} 1) .
$$

So we sometimes refer to $(\mathrm{C} 1)$ as "the Screening-Off Condition" and to this approach more generally as "the Screening-Off Approach". Intuitively, $\left(\mathrm{C} 1^{*}\right)$ means that once truth or falsity of $\mathrm{H} 1$ is known, $\mathrm{E}$ is irrelevant to the probability of $\mathrm{H} 2$. In other words, E affects the probability of $\mathrm{H} 2$ only indirectly through its impact on H1. Clearly, since confirmation-IF is transitive under (C1), and since $(\mathrm{C} 1)$ is weaker than $\left(\mathrm{C} 1^{*}\right)$, confirmation-IF is transitive under $\left(\mathrm{C} 1^{*}\right)$ as well. ${ }^{9}$ It is not surprising that confirmation-IF is transitive under $(\mathrm{C} 1 *)$ : if $\mathrm{E}$ raises the probability of $\mathrm{H} 1$, and $\mathrm{H} 1$ in turn raises the probability of $\mathrm{H} 2$, while $\mathrm{E}$ affects the probability of $\mathrm{H} 2$ only indirectly through its impact on $\mathrm{H} 1$, then $\mathrm{E}$ raises the probability of $\mathrm{H} 2$. The weaker condition $(\mathrm{C} 1)$ allows $\mathrm{E}$ to affect the probability of $\mathrm{H} 2$ even after truth or falsity of $\mathrm{H} 1$ is known, but the additional impact on $\mathrm{H} 2$ must be positive. It is therefore not surprising either that confirmation-IF is transitive under (C1).

How about the special case where H1 entails H2? Since confirmation-IF is transitive under (C1) in the general case, it is also transitive under $(\mathrm{C} 1)$ in the special case (thus under $(\mathrm{C} 1 *)$ in the special case). There are two other conditions known to ensure transitivity of confirmation-IF in the special case:

$$
\begin{aligned}
& \operatorname{Pr}(\mathrm{H} 2)<\operatorname{Pr}(\mathrm{H} 1 \mid \mathrm{E}) . \\
& \operatorname{Pr}(\mathrm{H} 2 \wedge \neg \mathrm{H} 1 \mid \mathrm{E}) \geq \operatorname{Pr}(\mathrm{H} 2 \wedge \neg \mathrm{H} 1) .
\end{aligned}
$$

It is easy to see why (C2) makes confirmation-IF transitive in the special case: $\operatorname{Since} \operatorname{Pr}(\mathrm{H} 1 \mid \mathrm{E}) \leq$ $\operatorname{Pr}(\mathrm{H} 2 \mid$ E) from the condition $\mathrm{H} 1 \mid-\mathrm{H} 2$ of the special case, (C2) $\operatorname{Pr}(\mathrm{H} 2)<\operatorname{Pr}(\mathrm{H} 1 \mid$ E) ensures that

${ }^{7}$ We have in mind, of course, nontrivial such conditions and not, say, the condition that $\mathrm{E}$ confirms-IF $\mathrm{H} 2$ as a condition for transitivity in confirmation-IF in the general case.

${ }^{8}$ See Roche (2012a).

${ }^{9}$ That confirmation-IF is transitive under $(\mathrm{C} 1 *)$ is shown in Shogenji (2003). 
$\operatorname{Pr}(\mathrm{H} 2)<\operatorname{Pr}(\mathrm{H} 2 \mid \mathrm{E})$, or E confirms-IF H2. ${ }^{10}$ We call (C2) "the Dragging Condition", and the approach more generally "the Dragging Approach", for the reason that as E raises the probability of $\mathrm{H} 1$, the probability of $\mathrm{H} 2$ gets dragged because of the entailment $\mathrm{H} 1 \mid-\mathrm{H} 2 .{ }^{11}$ In the case of (C3), we note that $\operatorname{Pr}(\mathrm{H} 2)=\operatorname{Pr}(\mathrm{H} 2 \wedge \mathrm{H} 1)+\operatorname{Pr}(\mathrm{H} 2 \wedge \neg \mathrm{H} 1)$ from the principle of total probability, and hence $\operatorname{Pr}(\mathrm{H} 2)=\operatorname{Pr}(\mathrm{H} 1)+\operatorname{Pr}(\mathrm{H} 2 \wedge \neg \mathrm{H} 1)$ from the condition $\mathrm{H} 1 \mid-\mathrm{H} 2$. Similarly, $\operatorname{Pr}(\mathrm{H} 2 \mid \mathrm{E})=$ $\operatorname{Pr}(\mathrm{H} 2 \wedge \mathrm{H} 1 \mid \mathrm{E})+\mathrm{P}(\mathrm{H} 2 \wedge \neg \mathrm{H} 1 \mid \mathrm{E})=\operatorname{Pr}(\mathrm{H} 1 \mid \mathrm{E})+\mathrm{P}(\mathrm{H} 2 \wedge \neg \mathrm{H} 1 \mid \mathrm{E})$. But $\operatorname{Pr}(\mathrm{H} 1)<\operatorname{Pr}(\mathrm{H} 1 \mid \mathrm{E})$ from the first antecedent of transitivity. So, (C3) $\operatorname{Pr}(\mathrm{H} 2 \wedge \neg \mathrm{H} 1 \mid \mathrm{E}) \geq \operatorname{Pr}(\mathrm{H} 2 \wedge \neg \mathrm{H} 1)$ ensures that $\operatorname{Pr}(\mathrm{H} 2 \mid$ E) $>\operatorname{Pr}(\mathrm{H} 2)$, or E confirms-IF H2. ${ }^{12}$ We call (C3) "the Addition Condition", and the approach more generally "the Addition Approach", since $\operatorname{Pr}(\mathrm{H} 2 \wedge \neg \mathrm{H} 1 \mid \mathrm{E})$ and $\operatorname{Pr}(\mathrm{H} 2 \wedge \neg \mathrm{H} 1)$ in $(\mathrm{C} 3)$ are additions to $\operatorname{Pr}(\mathrm{H} 1 \mid \mathrm{E})$ and $\operatorname{Pr}(\mathrm{H} 1)$ to make up $\operatorname{Pr}(\mathrm{H} 2 \mid \mathrm{E})$ and $\operatorname{Pr}(\mathrm{H} 2)$, respectively.

In this paper we are going to assess the strengths and weaknesses of the three conditions. First, we investigate whether (C1), (C2), and (C3) are also conditions for transitivity in confirmation-IF\&SF or confirmation-TSF in the special case (Section 2). Next, we investigate whether (C1) is also a condition for transitivity in confirmation-SF, confirmation-IF\&SF, or confirmation-TSF in the general case; and whether (C2) and (C3) are conditions for transitivity in confirmation-IF, confirmation-SF, confirmation-IF\&SF, or confirmation-TSF in the general case (Section 3). We then argue that the Screening-Off Approach by (C1) is preferable in certain important respects to the alternatives by $(\mathrm{C} 2)$ and $(\mathrm{C} 3)$, and illustrate some of the points by applying (C1), (C2) and (C3) to G. E. Moore's famous "proof" of the existence of a material world (Section 4).

\section{The special case}

Each of $(\mathrm{C} 1),(\mathrm{C} 2)$, and $(\mathrm{C} 3)$ is a condition for transitivity in confirmation-IF in the special case in that:

Theorem 1 Let (X) be any of (C1)-(C3). If (a) E confirms-IF H1, (b) H1 confirms-IF H2, (c) H1 entails H2, and (d) (X) holds, then E confirms-IF H2.

(For proof of Theorem 1, see Section 1 above and references given there.) A few comments are in order. First, (b) is redundant given (c), since, as mentioned earlier, if $\mathrm{H} 1$ entails $\mathrm{H} 2$, then $\mathrm{H} 1$ confirms-IF H2 (except for the uninteresting cases we have set aside). We retain (b) to make it clear that $(\mathrm{C} 1),(\mathrm{C} 2)$, and $(\mathrm{C} 3)$ are conditions for transitivity in confirmation-IF in the special case where $\mathrm{H} 1$ entails H2. Second, when $\mathrm{H} 1$ entails $\mathrm{H} 2, \operatorname{Pr}(\mathrm{H} 2 \mid \mathrm{E} \wedge \mathrm{H} 1)=1=\operatorname{Pr}(\mathrm{H} 2 \mid \mathrm{H} 1)$, thus the

${ }^{10}$ Cf. Kotzen (2012, p. 69), Kukla (1998, secs. 4.2, 4.3, and 6.2), and Moretti (2002, p. 160, 2012, sec. 5).

${ }^{11}$ We are following Kotzen (2012) in calling (C2) "the Dragging Condition".

${ }^{12}$ Cf. Kotzen (2012, p. 66). 
first conjunct of $(\mathrm{C} 1)$ - $\operatorname{Pr}(\mathrm{H} 2 \mid \mathrm{E} \wedge \mathrm{H} 1) \geq \operatorname{Pr}(\mathrm{H} 2 \mid \mathrm{H} 1)$ —already holds. So, where (X) is (C1), Theorem 1 could be rewritten as "If (a) E confirms-IF H1, (b) H1 confirms-IF H2, (c) H1 entails $\mathrm{H} 2$, and (d*) $\operatorname{Pr}(\mathrm{H} 2 \mid \mathrm{E} \wedge \neg \mathrm{H} 1) \geq \operatorname{Pr}(\mathrm{H} 2 \mid \neg \mathrm{H} 1)$, then E confirms-IF H2”. Third, where (X) is (C2), (a) is redundant given (c) and (d). If $\mathrm{H} 1$ entails $\mathrm{H} 2$, and (C2) holds, it follows that $\operatorname{Pr}(\mathrm{H} 1) \leq \operatorname{Pr}(\mathrm{H} 2)$ $<\operatorname{Pr}(\mathrm{H} 1 \mid \mathrm{E})$, hence $\operatorname{Pr}(\mathrm{H} 1)<\operatorname{Pr}(\mathrm{H} 1 \mid \mathrm{E}){ }^{13}$

Theorem 1 states that confirmation-IF is transitive in the special case provided $(\mathrm{C} 1),(\mathrm{C} 2)$, or (C3) holds. The question now is whether these conditions are also conditions for transitivity in confirmation-IF\&SF or confirmation-TSF in the special case.

The answer is affirmative. (C1), (C2), and (C3) are conditions for confirmation-IF\&SF and confirmation-TSF in the special case in that:

Theorem 2 Let (X) be any of (C1)-(C3). If (a) E confirms-IF\&SF H1, (b) H1 confirmsIF\&SF H2, (c) H1 entails H2, and (d) (X) holds, then E confirms-IF\&SF $\mathrm{H} 2{ }^{14}$

Theorem 3 Let (X) be any of (C1)-(C3). If (a) E confirms-TSF H1, (b) H1 confirmsTSF H2, (c) H1 entails H2, and (d) (X) holds, then E confirms-TSF H2.

(For proof of Theorem 2, see Appendix A. For proof of Theorem 3, see Appendix B.) These theorems are robust in that they hold regardless of the value specified for $t$.

For completeness, and ease of reference, we note that:

Theorem 4 If (a) E confirms-SF H1, (b) H1 confirms-SF H2, and (c) H1 entails H2, then E confirms-SF H2.

(For proof of Theorem 4, see Section 1 above.) This theorem, like Theorem 2 and Theorem 3, is robust in that it holds regardless of the value specified for $\mathbf{t}$.

There is a clear sense in which Theorem 4 is a mere closure principle whereas Theorem 2 and Theorem 3 are transmission principles. ${ }^{15}$ All positive instances of Theorem 4 are cases in which $\mathrm{H} 2$ is rationally acceptable given E. ${ }^{16}$ But, in some such cases E reduces the probability of $\mathrm{H} 2$, so that the probabilistic boost $\mathrm{H} 1$ receives from $\mathrm{E}$ is not transmitted to $\mathrm{H} 2$ through entailment. Recall the zoo case from above, where Smith is visiting the local zoo, E is the claim "It appears to me (Smith) visually as if the animal in the pen before me is a zebra", H1 is the claim "The animal in

${ }^{13}$ Cf. Kotzen (2012, p. 72, n. 22).

${ }^{14}$ Luca Moretti (2012, sec. 5) establishes a principle similar to Theorem 2 where (X) is (C2). It can be put thus: If (a) $\operatorname{Pr}(\mathrm{H} 2)>\mathbf{t}$, (b) $\operatorname{Pr}(\mathrm{H} 1 \mid \mathrm{E})>\operatorname{Pr}(\mathrm{H} 1)$, (c) $\operatorname{Pr}(\mathrm{H} 1 \mid \mathrm{E})>\mathbf{t}$, (d) H1 entails H2, and (e) (C2) holds, then $\operatorname{Pr}(\mathrm{H} 2 \mid \mathrm{E})>\mathrm{P}(\mathrm{H} 2)$.

${ }^{15}$ Theorem 4 is essentially the same as "Closure*" in Chandler (2010, p. 337, n. 5).

${ }^{16}$ Here and throughout the paper when we speak of positive instances of transitivity, we have in mind nonvacuous positive instances. 
the pen before me (Smith) is a zebra", and H2 is the claim "It is not the case that the animal in the pen before me (Smith) is a mule cleverly disguised to look like a zebra". $\operatorname{Pr}(\mathrm{H} 1 \mid \mathrm{E})>\mathbf{t}$, thus H1 is rationally acceptable given E. By Theorem 4 it follows that, since H1 confirms-SF and entails H2, $\operatorname{Pr}(\mathrm{H} 2 \mid \mathrm{E})>\mathbf{t}$ and so $\mathrm{H} 2$ is rationally acceptable given E. But, as explained above (Section 1), E reduces the probability of $\mathrm{H} 2$. All positive instances of Theorem 2 and Theorem 3, by contrast, are cases where not only is $\mathrm{H} 2$ rationally acceptable given $\mathrm{E}$ but also $\mathrm{E}$ raises the probability of $\mathrm{H} 2 .{ }^{17}$ We acknowledge, however, that the use of the term "transmission" varies in the literature and as some use the term, Theorem 2 and Theorem 3 are not transmission principles. ${ }^{18}$ We return to this issue below in Section 4. Our claim for now is just that Theorem 2 and Theorem 3 are in one clear sense transmission principles, namely, all positive instances of Theorem 2 and Theorem 3 are cases in which $\mathrm{E}$ raises the probability of $\mathrm{H} 2$.

\section{The general case}

We turn now to the general case. Here the news is almost all bad. We have:

Theorem 5 A If (a) E confirms-IF H1, (b) H1 confirms-IF H2, and (c) (C1) holds, then E confirms-IF H2.

$B$ Let (X) be any of (C2)-(C3). It is not the case that: If (a) E confirms-IF H1, (b) H1 confirms-IF H2, and (c) (X) holds, then E confirms-IF H2.

Theorem 6 Let $(\mathrm{X})$ be any of $(\mathrm{C} 1)-(\mathrm{C} 3)$. It is not the case that: If (a) E confirms-IF\&SF H1, (b) H1 confirms-IF\&SF H2, and (c) (X) holds, then E confirms-IF\&SF $\mathrm{H} 2$.

${ }^{17}$ Each of $(\mathrm{C} 1),(\mathrm{C} 2)$, and $(\mathrm{C} 3)$ fails to hold in the zoo case. That (C1) fails to hold follows from the fact that $\operatorname{Pr}(\mathrm{H} 2 \mid \mathrm{E} \wedge \neg \mathrm{H} 1)<\operatorname{Pr}(\mathrm{H} 2 \mid \neg \mathrm{H} 1)$; E increases the probability of $\neg \mathrm{H} 2$ given $\neg \mathrm{H} 1$, and, so, decreases the probability of $\mathrm{H} 2$ given $\neg \mathrm{H} 1$. That (C2) fails to hold follows from the fact that $\operatorname{Pr}(\mathrm{E} \mid \mathrm{H} 1)=\operatorname{Pr}(\mathrm{E} \mid \neg \mathrm{H} 2)$, thus $\operatorname{Pr}(\mathrm{E} \mid \mathrm{H} 1) \leq \operatorname{Pr}(\mathrm{E} \mid \neg \mathrm{H} 2)$; Kotzen (2012, pp. 81-82) shows that (where E confirms-IF H1) if $\operatorname{Pr}(\mathrm{E} \mid \mathrm{H} 1) \leq \operatorname{Pr}(\mathrm{E} \mid \neg \mathrm{H} 2)$, then (C2) does not hold. $\operatorname{Pr}(\neg \mathrm{H} 2 \wedge$ $\neg \mathrm{H} 1 \mid \mathrm{E})>\operatorname{Pr}(\neg \mathrm{H} 2 \wedge \neg \mathrm{H} 1)$ and $\operatorname{Pr}(\mathrm{H} 2 \wedge \mathrm{H} 1 \mid \mathrm{E})=\operatorname{Pr}(\mathrm{H} 1 \mid \mathrm{E})>\operatorname{Pr}(\mathrm{H} 1)=\operatorname{Pr}(\mathrm{H} 2 \wedge \mathrm{H} 1)$, so, since $\operatorname{Pr}(\neg \mathrm{H} 2 \wedge \mathrm{H} 1 \mid \mathrm{E})=0=\operatorname{Pr}(\neg \mathrm{H} 2 \wedge \mathrm{H} 1)$, it follows that $\operatorname{Pr}(\mathrm{H} 2 \wedge \neg \mathrm{H} 1 \mid \mathrm{E})<\operatorname{Pr}(\mathrm{H} 2 \wedge \neg \mathrm{H} 1)$, thus (C3) fails to hold.

${ }^{18}$ The extant literature on transmission failure is extensive. See, e.g., Beebee (2001), Brown (2003, 2004), Cling (2002), Coliva (2011), Davies (1998, 2000, 2003, 2004), Dretske (2005a, 2005b), Ebert (2005), Hale (2000), Hawthorne (2005), Kotzen (2012, sec. 6), McKinsey (2003), McLaughlin (2003), Neta (2007), Peacocke (2004, Ch. 4, pp. 112-115), Pryor (2004), Sainsbury (2000), Schiffer (2004), Silins (2005, 2007), Smith (2009), Suarez (2000), Tucker (2010a, 2010b), White (2006, sec. 5), and Wright (1985, 2000a, 2000b, 2002, 2003, 2004, 2007, 2011). For discussion of how to formalize the issue of transmission failure, see Chandler (2010), Moretti (2012), Moretti and Piazza (2011), and Okasha (2004). Cf. Pynn (2011). 
Theorem 7 Let $(\mathrm{X})$ be any of $(\mathrm{C} 1)-(\mathrm{C} 3)$. It is not the case that: If (a) E confirms-TSF H1, (b) H1 confirms-TSF H2, and (c) (X) holds, then E confirms-TSF H2.

(For proof of Theorem 5A, see Section 1 above and references given there. For proof of Theorem 5B, see Appendix C. For proof of Theorem 6, see Appendix D. For proof of Theorem 7, see Appendix E.) So, whereas in the special case each of (C1), (C2), and (C3) is a condition for transitivity in confirmation-IF, in the general case (C1) but neither (C2) nor (C3) is a condition for transitivity in confirmation-IF, and whereas in the special case each of (C1), (C2), and (C3) is a condition for transitivity in confirmation-IF\&SF and confirmation-TSF, in the general case none of (C1), (C2), and (C3) is a condition for transitivity in confirmation-IF\&SF or confirmationTSF. ${ }^{19}$ We noted above that Theorem 2, Theorem 3, and Theorem 4 are robust in that they hold regardless of the value specified for $\mathbf{t}$. The same is true of Theorem 6 and Theorem 7.

Confirmation-SF is transitive in the special case but not in the general case. It remains to be determined whether $(\mathrm{C} 1),(\mathrm{C} 2)$, and $(\mathrm{C} 3)$ are conditions for transitivity in confirmation-SF in the general case. The answer is negative:

Theorem 8 Let $(\mathrm{X})$ be any of (C1)-(C3). It is not the case that: If (a) E confirms-SF H1, (b) H1 confirms-SF H2, and (c) (X) holds, then E confirms-SF H2.

(For proof of Theorem 8, see Appendix F.)

In sum, the lone piece of good news on the general case is Theorem 5A: $(\mathrm{C} 1)$ is a condition for transitivity in confirmation-IF in the general case. We argue below that this is an important respect in which $(\mathrm{C} 1)$ is preferable to $(\mathrm{C} 2)$ and $(\mathrm{C} 3)$.

\section{Superiority of the Screening-Off Approach}

\subsection{Cases where $\mathrm{H} 1$ does not entail $\mathrm{H} 2$}

The general case includes the special case, but also includes cases where $\mathrm{H} 1$ does not entail $\mathrm{H} 2$. The Screening-Off Approach by (C1) is superior to the Dragging Approach by (C2) and the Addition Approach by (C3) in part because (C1) is a condition for transitivity in confirmation-IF

${ }^{19}$ Compare Theorem 3 and Theorem 7. The latter shows that the antecedent condition that H1 entails $\mathrm{H} 2$ is essential to the former, but does not show that the same is true of the antecedent condition that $\mathrm{H} 1$ confirms-TSF $\mathrm{H} 2$. We noted earlier that it follows from $\mathrm{H} 1 \mid-\mathrm{H} 2$ that $\mathrm{H} 1$ confirms-IF H2 (except for the uninteresting cases), but it does not follow that H1 confirms-TSF H2. So, (b) is not redundant. Moreover, the argument given in Appendix E for Theorem 7 does not involve cases where $\mathrm{H} 1$ entails $\mathrm{H} 2$, and therefore does not itself imply that there can be cases where (a) E confirms-TSF H1, (c) H1 entails H2, and (d) (C1), (C2), and (C3) all hold, and yet E does not confirm-TSF H2. It can be shown, however, that such cases are possible-regardless of the value specified for $\mathbf{t}$. Due to space considerations we omit the proof. 
in the general case and not just in the special case, hence is wider in application in the general case than are (C2) and (C3). This advantage can be illustrated by considering a second special casethe case where $\mathrm{H} 2$ entails $\mathrm{H} 1$ instead of $\mathrm{H} 1$ entailing $\mathrm{H} 2$.

The "Converse Consequence Condition", when understood in terms of confirmation-IF, is the thesis:

(CCC) If (a) E confirms-IF H1 and (b) H2 entails H1, then E confirms-IF H2.

(CCC) has some initial plausibility. But it is easy to see that (CCC) is false. Suppose a card is randomly drawn from a standard deck of cards. Let $\mathrm{E}$ be the claim "The card drawn is a Heart", H1 be the claim "The card drawn is a Red", and H2 be the claim "The card drawn is a Diamond". $\operatorname{Pr}(\mathrm{H} 1 \mid \mathrm{E})=1>\operatorname{Pr}(\mathrm{H} 1)=.5$. $\mathrm{H} 2$ entails H1. But $\operatorname{Pr}(\mathrm{H} 2 \mid \mathrm{E})=0<\operatorname{Pr}(\mathrm{H} 2)=.25 .{ }^{20}$

When $\mathrm{H} 2$ entails H1, H1 confirms-IF H2 (except, as usual, for the uninteresting cases), and confirmation-IF holds trivially if $\mathrm{H} 1$ and $\mathrm{H} 2$ entail each other. ${ }^{21}$ So, the point that (CCC) is false can be put as follows: Confirmation-IF is not transitive in the case where $\mathrm{H} 2$ entails $\mathrm{H} 1$ but $\mathrm{H} 1$ does not entail H2. It follows from Theorem 5A, however, that (C1) is a condition for transitivity in confirmation-IF in the case where $\mathrm{H} 2$ entails $\mathrm{H} 1$ in that:

(CCC*) If (a) E confirms-IF H1, (b) H2 entails H1, and (c) (C1) holds, then E confirmsIF H2.

In the card case above, $(\mathrm{C} 1)$ does not hold because $\operatorname{Pr}(\mathrm{H} 2 \mid \mathrm{E} \wedge \mathrm{H} 1)=0<\operatorname{Pr}(\mathrm{H} 2 \mid \mathrm{H} 1)=.5$ and $\operatorname{Pr}(\mathrm{H} 2 \mid \mathrm{E} \wedge \neg \mathrm{H} 1)$ is undefined. In contrast, neither $(\mathrm{C} 2)$ nor $(\mathrm{C} 3)$ is a condition for transitivity in confirmation-IF in the general case. Of course, it does not follow from this that neither (C2) nor (C3) is a condition for transitivity in confirmation-IF in the case where $\mathrm{H} 2$ entails $\mathrm{H} 1$. But in fact this is true. Take the card case above. (C2) holds, since $\operatorname{Pr}(\mathrm{H} 2)=.25<\operatorname{Pr}(\mathrm{H} 1 \mid \mathrm{E})=1$, and (C3) holds, given that $\operatorname{Pr}(\mathrm{H} 2 \wedge \neg \mathrm{H} 1 \mid \mathrm{E})=0=\operatorname{Pr}(\mathrm{H} 2 \wedge \neg \mathrm{H} 1)$.

We take this difference between $(\mathrm{C} 1)$ on one hand and (C2) and (C3) on the other to be significant. Though (CCC) is false, there are many cases where E confirms-IF H1, and H2 entails H1, and it seems that E confirms-IF H2. (C1) can help with such cases but neither (C2) nor (C3) can. ${ }^{22}$ Here is an example. A card is randomly drawn from a standard deck of cards. Smith is highly trustworthy (on matters concerning cards). E is the claim "Smith testified that the card

\footnotetext{
${ }^{20}$ The Converse Consequence Condition is introduced and rejected in Hempel (1965).

${ }^{21}$ When $\mathrm{H} 1$ and $\mathrm{H} 2$ are mutually-entailing, $\operatorname{Pr}(\mathrm{H} 1)=\operatorname{Pr}(\mathrm{H} 2)$ and $\operatorname{Pr}(\mathrm{H} 1 \mid \mathrm{E})=\operatorname{Pr}(\mathrm{H} 2 \mid \mathrm{E})$, in which case if $\operatorname{Pr}(\mathrm{H} 1 \mid \mathrm{E})>\operatorname{Pr}(\mathrm{H} 1)$, it follows that $\operatorname{Pr}(\mathrm{H} 2 \mid \mathrm{E})>\operatorname{Pr}(\mathrm{H} 2)$. Counterexamples to (CCC) are thus cases where $\mathrm{H} 1$ and $\mathrm{H} 2$ are not mutually-entailing. For relevant discussion, see Milne (2000).

${ }^{22}(\mathrm{C} 1 *)$, like $(\mathrm{C} 1)$, is a condition for transitivity in confirmation-IF in the case where $\mathrm{H} 2$ entails H1. But there are cases of transitivity in confirmation-IF in the case where $\mathrm{H} 2$ entails $\mathrm{H} 1$ where $(\mathrm{C} 1)$ holds but $\left(\mathrm{C} 1^{*}\right)$ does not.
} 
drawn is a Red". $\mathrm{H} 1$ is the claim "The card drawn is a Red". $\mathrm{H} 2$ is the claim "The card drawn is a Heart". E confirms-IF H1. H1 in turn confirms-IF and is entailed by H2. (CCC) is open to counterexample, but this case, it seems, is not among them. (C1) can provide some guidance here. $\operatorname{Pr}(\mathrm{H} 2 \mid \mathrm{E} \wedge \mathrm{H} 1)=1 / 2=\operatorname{Pr}(\mathrm{H} 2 \mid \mathrm{H} 1) . \operatorname{Pr}(\mathrm{H} 2 \mid \mathrm{E} \wedge \neg \mathrm{H} 1)=0=\operatorname{Pr}(\mathrm{H} 2 \mid \neg \mathrm{H} 1)$. So (C1) holds. Therefore, by $\left(\mathrm{CCC}^{*}\right)$, it follows that, just as it seems, $\operatorname{Pr}(\mathrm{H} 2 \mid \mathrm{E})>\operatorname{Pr}(\mathrm{H} 2)$.

This example is an instance of a "testimonial/memorial/perceptual" schema where: (i) E is a testimonial claim of the form "S testified that H1", or a memorial-appearance claim of the form "It appears to S memorially as if H1", or a perceptual-appearance claim of the form "It appears to S visually as if $\mathrm{H} 1$ ", or "It appears to S auditorily as if $\mathrm{H1}$ ", etc., where $\mathrm{S}$ is highly trustworthy, or S's memory is highly reliable, or S's vision, or hearing, etc., is highly reliable; (ii) H2 entails H1 but not vice versa. Many instances of this schema are cases where (CCC*) applies (hence Theorem $5 A$ applies). No instances of this schema are cases where (C2) or (C3) can help. ${ }^{23}$

\subsection{Cases where $\mathrm{H} 1$ entails $\mathrm{H} 2$}

We observed in support of the Screening-Off Approach that (C1) has a much broader range of application than (C2) and (C3) in the general case. This advantage disappears in the special case where $\mathrm{H} 1$ entails $\mathrm{H} 2$ because as long as $\mathrm{H} 1$ entails $\mathrm{H} 2$, confirmation in all four sensesconfirmation-IF, confirmation-SF, confirmation-IF \&SF, and confirmation-TSF-is transitive under any of the three conditions - (C1), (C2), and (C3). However, we argue that the ScreeningOff Approach is preferable even in the special case where $\mathrm{H} 1$ entails H2. Our argument has two stages. First, we show that (C1) and (C3) are much easier to verify than (C2). Second, we prove that (C3) entails (C1) in the special case where H1 entails H2 (assuming E confirms-IF H1) but (C1) does not entail (C3), so that (C1) has a broader range of application than does (C3).

We begin with the ease of application. Superficially, it seems to require more work to verify (C1) than to verify $(\mathrm{C} 2)$ or (C3) because (C1) has two components while (C2) and (C3) have only one component. However, as noted above in Section 2, one of the two components of $(\mathrm{C} 1), \operatorname{Pr}(\mathrm{H} 2$ $\mid \mathrm{E} \wedge \mathrm{H} 1) \geq \operatorname{Pr}(\mathrm{H} 2 \mid \mathrm{H} 1)$, holds trivially in the special case since $\operatorname{Pr}(\mathrm{H} 2 \mid \mathrm{E} \wedge \mathrm{H} 1)=\operatorname{Pr}(\mathrm{H} 2 \mid \mathrm{H} 1)=$ 1 when $\mathrm{H} 1$ entails $\mathrm{H} 2$. So, there is only one condition to verify in $(\mathrm{C} 1)$. The conditions we need to verify are, then:
$\left(\mathrm{C} 1^{\dagger}\right)$
$\operatorname{Pr}(\mathrm{H} 2 \mid \mathrm{E} \wedge \neg \mathrm{H} 1) \geq \operatorname{Pr}(\mathrm{H} 2 \mid \neg \mathrm{H} 1)$.
$\operatorname{Pr}(\mathrm{H} 2)<\operatorname{Pr}(\mathrm{H} 1 \mid \mathrm{E})$.

$$
\operatorname{Pr}(\mathrm{H} 2 \wedge \neg \mathrm{H} 1 \mid \mathrm{E}) \geq \operatorname{Pr}(\mathrm{H} 2 \wedge \neg \mathrm{H} 1) .
$$

It may still appear that (C2) is the simplest and thus the easiest to verify, but note that no proposition appears on both sides of the inequality in (C2). We are making an entirely

\footnotetext{
${ }^{23}$ Testimonial/memorial/perceptual cases are discussed in Roche (2012a) and Shogenji
} (2003). 
heterogeneous comparison in (C2). There is no indirect way of comparing the two sides, either. We know, of course, that $\operatorname{Pr}(\mathrm{H} 1) \leq \operatorname{Pr}(\mathrm{H} 2)$ when $\mathrm{H} 1$ entails $\mathrm{H} 2$. We also know that $\operatorname{Pr}(\mathrm{H} 1)<$ $\operatorname{Pr}(\mathrm{H} 1 \mid$ E) when E confirms-IF H1, confirms-IF\&SF H1, or confirms-TSF H1. So, both $\operatorname{Pr}(\mathrm{H} 2)$ and $\operatorname{Pr}(\mathrm{H} 1 \mid \mathrm{E})$ are greater than or equal to $\operatorname{Pr}(\mathrm{H} 1)$, but that does not help us determine whether $\operatorname{Pr}(\mathrm{H} 2)<\operatorname{Pr}(\mathrm{H} 1 \mid \mathrm{E})$. In order to verify $(\mathrm{C} 2)$, then, we need to make independent quantitative estimates of $\operatorname{Pr}(\mathrm{H} 2)$ and $\operatorname{Pr}(\mathrm{H} 1 \mid \mathrm{E})$, and compare the results. In contrast, the same proposition appears on both sides of the inequality in $\left(\mathrm{C}^{\dagger}\right)$ and $(\mathrm{C} 3) .\left(\mathrm{C}^{\dagger}\right)$ compares the probabilities of the same proposition $\mathrm{H} 2$ on different conditions. Even these different conditions contain the same proposition $\neg \mathrm{H} 1$. As a result, the task is much easier. We only need to assess the impact of the additional condition $\mathrm{E}$ on the probability of $\mathrm{H} 2$ against the background $\neg \mathrm{H} 1$. All we need to know to verify $\left(\mathrm{C}^{\dagger}\right)$ is that $\mathrm{E}$ has no negative impact in this setting. The assessment is therefore entirely qualitative, with no need for making independent quantitative estimates of $\operatorname{Pr}(\mathrm{H} 2 \mid \mathrm{E} \wedge \neg \mathrm{H} 1)$ and $\operatorname{Pr}(\mathrm{H} 2 \mid \neg \mathrm{H} 1)$. Like $\left(\mathrm{C}^{\dagger}\right) —$ and unlike $(\mathrm{C} 2) —(\mathrm{C} 3)$ requires no independent quantitative estimates of $\operatorname{Pr}(\mathrm{H} 2 \wedge \neg \mathrm{H} 1 \mid \mathrm{E})$ and $\operatorname{Pr}(\mathrm{H} 2 \wedge \neg \mathrm{H} 1)$. All we need to know to verify (C3) is that E has no negative impact on $\mathrm{H} 2 \wedge \neg \mathrm{H} 1$. We conclude that $\left(\mathrm{C}^{\dagger}\right)$ and $(\mathrm{C} 3)$ are much easier to verify than $(\mathrm{C} 2)^{24}$

The comparative ease of application is not clear-cut between $\left(\mathrm{C} 1^{\dagger}\right)$ and $(\mathrm{C} 3)$. In $\left(\mathrm{C} 1^{\dagger}\right)$ we assess the impact of E against the background $\neg \mathrm{H} 1$, while in (C3) we need not take any background information into account. The assessment in (C3) is less complicated in this regard. However, the proposition $\mathrm{H} 2 \wedge \neg \mathrm{H} 1$, on which the impact of $\mathrm{E}$ is assessed in (C3), is a conjunction, while the proposition $\mathrm{H} 2$ in $\left(\mathrm{C}^{\dagger}\right)$ is simple. Since assessing the impact of the evidence on a conjunction is often difficult, we believe $\left(\mathrm{Cl}^{\dagger}\right)$ is somewhat easier to verify than (C3) overall. Some may disagree with this appraisal, but we need not dwell on the issue further because there is a decisive reason to prefer $\left(\mathrm{C}^{\dagger}\right)$ over (C3): If E confirms-IF H1, confirms-IF\&SF $\mathrm{H} 1$, or confirms-TSF H1, then (C3) entails $\left(\mathrm{C}^{\dagger}\right)$ while $\left(\mathrm{C} 1^{\dagger}\right)$ does not entail (C3). This means that provided E confirms-IF H1, confirms-IF\&SF H1, or confirms-TSF H1, then whenever (C3) holds, $\left(\mathrm{C} 1^{\dagger}\right)$ holds; while there are cases where $\left(\mathrm{Cl}^{\dagger}\right)$ holds but (C3) does not. So, we should make $\left(\mathrm{C} 1^{\dagger}\right)$ our focus, and regard $(\mathrm{C} 3)$ as one way of verifying $\left(\mathrm{C}^{\dagger}\right)$. The reason for their entailment relation is as follows. $\operatorname{Pr}(\mathrm{H} 2 \wedge \neg \mathrm{H} 1 \mid \mathrm{E})=\operatorname{Pr}(\mathrm{H} 2 \mid \neg \mathrm{H} 1 \wedge \mathrm{E}) \operatorname{Pr}(\neg \mathrm{H} 1 \mid \mathrm{E})$ by the chain rule, and $\operatorname{Pr}(\mathrm{H} 2 \wedge$ $\neg \mathrm{H} 1)=\operatorname{Pr}(\mathrm{H} 2 \mid \neg \mathrm{H} 1) \operatorname{Pr}(\neg \mathrm{H} 1)$ also by the chain rule. So, (C3) $\operatorname{Pr}(\mathrm{H} 2 \wedge \neg \mathrm{H} 1 \mid \mathrm{E}) \geq \operatorname{Pr}(\mathrm{H} 2 \wedge \neg \mathrm{H} 1)$ is equivalent to $\operatorname{Pr}(\mathrm{H} 2 \mid \neg \mathrm{H} 1 \wedge \mathrm{E}) \operatorname{Pr}(\neg \mathrm{H} 1 \mid \mathrm{E}) \geq \operatorname{Pr}(\mathrm{H} 2 \mid \neg \mathrm{H} 1) \mathrm{P}(\neg \mathrm{H} 1)$. Meanwhile, if E confirms-IF H1, confirms-IF\&SF H1, or confirms-TSF H1, then E confirms-IF H1. This means that E disconfirms $\neg \mathrm{H} 1$, so that $\operatorname{Pr}(\neg \mathrm{H} 1 \mid \mathrm{E})<\operatorname{Pr}(\neg \mathrm{H} 1)$. In order to make $\operatorname{Pr}(\mathrm{H} 2 \mid \neg \mathrm{H} 1 \wedge \mathrm{E}) \operatorname{Pr}(\neg \mathrm{H} 1 \mid \mathrm{E}) \geq$ $\operatorname{Pr}(\mathrm{H} 2 \mid \neg \mathrm{H} 1) \operatorname{Pr}(\neg \mathrm{H} 1)$ while $\operatorname{Pr}(\neg \mathrm{H} 1 \mid \mathrm{E})<\operatorname{Pr}(\neg \mathrm{H} 1)$, it must be the case that $\operatorname{Pr}(\mathrm{H} 2 \mid \neg \mathrm{H} 1 \wedge \mathrm{E}) \geq$ $\operatorname{Pr}(\mathrm{H} 2 \mid \neg \mathrm{H} 1)$, which is $\left(\mathrm{Cl}^{\dagger}\right) .{ }^{25}$ The converse does not hold because it is possible that $\left(\mathrm{C} 1^{\dagger}\right) \operatorname{Pr}(\mathrm{H} 2$

${ }^{24}$ Cf. Kotzen (2012, secs. 3 and 4).

${ }^{25}$ In fact, it must be the case that $\operatorname{Pr}(\mathrm{H} 2 \mid \neg \mathrm{H} 1 \wedge \mathrm{E})>\operatorname{Pr}(\mathrm{H} 2 \mid \neg \mathrm{H} 1)$, which means that $(\mathrm{C} 1 *)$ fails to hold. So, if E confirms-IF H1, confirms-IF\&SF H1, or confirms-TSF H1, (C3) entails not$(\mathrm{C} 1 *)$. 
$\mid \neg \mathrm{H} 1 \wedge \mathrm{E}) \geq \operatorname{Pr}(\mathrm{H} 2 \mid \neg \mathrm{H} 1)$ but not $(\mathrm{C} 3) \operatorname{Pr}(\mathrm{H} 2 \mid \neg \mathrm{H} 1 \wedge \mathrm{E}) \operatorname{Pr}(\neg \mathrm{H} 1 \mid \mathrm{E}) \geq \operatorname{Pr}(\mathrm{H} 2 \mid \neg \mathrm{H} 1) \mathrm{P}(\neg \mathrm{H} 1)$ when the inequality $\operatorname{Pr}(\neg \mathrm{H} 1 \mid \mathrm{E})<\operatorname{Pr}(\neg \mathrm{H} 1)$ is sufficiently large. For those who are curious, there is no logical entailment between (C1) and (C2) even under the condition that E confirms-IF H1. As explained above, our reason in favor of $(\mathrm{C} 1)$ over $(\mathrm{C} 2)$ is the ease of application. To see that $(\mathrm{C} 1)$ does not entail (C2), take Kotzen's example of a failure of (C2):

Suppose that your confidence that the butler did it [H1] is .2 and that your confidence that someone on the mansion staff did it [H2] is .9. Some new evidence that somewhat incriminates the butler [E] might motivate you to increase your credence that the butler did it from .2 to .3. (Kotzen 2012, p. 88)

In this case $\mathrm{H} 1$ entails $\mathrm{H} 2$, and the Dragging Condition (C2) fails because $\operatorname{Pr}(\mathrm{H} 1 \mid \mathrm{E})=.3<.9=$ $\operatorname{Pr}(\mathrm{H} 2)$. Note, however, that this probability distribution is consistent with the additional condition that $\operatorname{Pr}(\mathrm{H} 2 \mid \neg \mathrm{H} 1 \wedge \mathrm{E})=\operatorname{Pr}(\mathrm{H} 2 \mid \neg \mathrm{H} 1)=7 / 9$, so that once the butler's innocence is established, the evidence that somewhat incriminates the butler becomes irrelevant, which makes $\left(\mathrm{Cl}^{\dagger}\right)$ true. So, it is possible that $(\mathrm{C} 1)$ is true while $(\mathrm{C} 2)$ is false. Next, to see that $(\mathrm{C} 2)$ does not entail $(\mathrm{C} 1)$, note that $\operatorname{Pr}(\mathrm{H} 2 \mid \mathrm{E})-\operatorname{Pr}(\mathrm{H} 2)=[\operatorname{Pr}(\mathrm{H} 2 \mid \mathrm{E})-\operatorname{Pr}(\mathrm{H} 1 \mid \mathrm{E})]+[\operatorname{Pr}(\mathrm{H} 1 \mid \mathrm{E})-\operatorname{Pr}(\mathrm{H} 2)]$. Meanwhile, $\operatorname{Pr}(\mathrm{H} 1 \mid \mathrm{E}) \leq$ $\operatorname{Pr}(\mathrm{H} 2 \mid \mathrm{E})$ from $\mathrm{H} 1 \mid-\mathrm{H} 2$. Consider a special case where $\operatorname{Pr}(\mathrm{H} 1 \mid \mathrm{E})=\operatorname{Pr}(\mathrm{H} 2 \mid \mathrm{E}) .{ }^{26}$ Under this condition, (C2) $\operatorname{Pr}(\mathrm{H} 2)<\operatorname{Pr}(\mathrm{H} 1 \mid \mathrm{E})$ is necessary and sufficient for $\operatorname{Pr}(\mathrm{H} 2 \mid \mathrm{E})>\operatorname{Pr}(\mathrm{H} 2)$, or $\mathrm{E}$ confirms-IF H2. However, even under the conditions $\mathrm{H} 1 \mid-\mathrm{H} 2$ and $\operatorname{Pr}(\mathrm{H} 1 \mid \mathrm{E})=\operatorname{Pr}(\mathrm{H} 2 \mid \mathrm{E}),\left(\mathrm{Cl}^{\dagger}\right)$ $\operatorname{Pr}(\mathrm{H} 2 \mid \neg \mathrm{H} 1 \wedge \mathrm{E}) \geq \operatorname{Pr}(\mathrm{H} 2 \mid \neg \mathrm{H} 1)$ is still only sufficient—and not necessary-for $\operatorname{Pr}(\mathrm{H} 2 \mid \mathrm{E})>$ $\operatorname{Pr}(\mathrm{H} 2)$ because even if $\operatorname{Pr}(\mathrm{H} 2 \mid \neg \mathrm{H} 1 \wedge \mathrm{E})<\operatorname{Pr}(\mathrm{H} 2 \mid \neg \mathrm{H} 1)$, E's positive indirect support for $\mathrm{H} 2$ through $\mathrm{H} 1$ can outweigh the negative impact $\operatorname{Pr}(\mathrm{H} 2 \mid \neg \mathrm{H} 1 \wedge \mathrm{E})-\operatorname{Pr}(\mathrm{H} 2 \mid \neg \mathrm{H} 1)$ that $\mathrm{E}$ has on $\mathrm{H} 2$ on condition of $\neg \mathrm{H} 1$. So, (C1) can be false while (C2) is true. (C2) does not entail (C1). ${ }^{27}$

\subsection{Moore's Proof}

We distinguished various senses of confirmation, and examined which sense of confirmation is transitive under which additional conditions. Based in part on these examinations, we made the case that the Screening-Off Condition, (C1), is the most important among the three conditions because of its generality and ease of application. In this subsection we illustrate some of these points with the example of "Moore's proof" that has been a major reason for the interest in transmission failure in the recent literature. We liberally interpret the proof as follows:

\section{MOORE}

\footnotetext{
${ }^{26}$ This does not require that $\mathrm{H} 2$ also logically entails $\mathrm{H} 1$.

${ }^{27}$ It can be shown, further, that even under the condition that E confirms-IF H1, there is no logical entailment between (C2) and (C3).
} 
E: My experience is that of a hand held up in front of my face.

$\mathrm{H} 1$ : Here is a hand.

$\mathrm{H} 2$ : There is a material world.

We make certain assumptions here. First, since other experiences that are similar to E would make $\mathrm{E}$ unnecessary for the support of $\mathrm{H} 2$, we assume for the sake of argument that $\mathrm{E}$ is the only evidence available for the existence of a material world. ${ }^{28} \mathrm{We}$ also assume for the sake of argument that $\mathrm{H} 1$ (Here is a hand) is not sufficiently firm on its own, but $E$ makes it sufficiently firm, i.e. $\operatorname{Pr}(\mathrm{H} 1) \leq \mathbf{t}$ and $\operatorname{Pr}(\mathrm{H} 1 \mid \mathrm{E})>\mathbf{t}$. So, E confirms H1 in all four senses-confirmation-IF, confirmation-SF, confirmation-IF\&SF, confirmation-TSF.

What we want to know is whether $\mathrm{E}$ also confirms $\mathrm{H} 2$ because of the relation between $\mathrm{H} 1$ and $\mathrm{H} 2$. Their relation in MOORE is entailment since the existence of a hand entails the existence of a material world. This makes confirmation-SF transitive with no additional condition: It follows from $\operatorname{Pr}(\mathrm{H} 1 \mid \mathrm{E})>\mathbf{t}, \operatorname{Pr}(\mathrm{H} 2 \mid \mathrm{H} 1)>\mathbf{t}$ and $\mathrm{H} 1 \mid--\mathrm{H} 2$, that $\operatorname{Pr}(\mathrm{H} 2 \mid \mathrm{E})>\mathbf{t}$. However, confirmation in the other three senses - confirmation-IF, confirmation-IF\&SF, confirmation-TSF-is not transitive in the absence of additional conditions even in the special case. So, it is possible that $\mathrm{E}$ confirms $\mathrm{H} 1, \mathrm{H} 1$ confirms $\mathrm{H} 2$, and $\mathrm{H} 1$ entails $\mathrm{H} 2$, and yet $\mathrm{E}$ fails to confirm $\mathrm{H} 2$. It has been suggested in the literature that this failure in the transmission of confirmation may explain why MOORE is ineffective as a proof of the existence of a material world, for E may not lend support for $\mathrm{H} 2$ after all. However, as we noted above, confirmation in these three senses is also transitive in the special case under the additional condition (C1), (C2) or (C3). The critical question we want to ask is whether any of the additional conditions holds in MOORE.

With regard to $(\mathrm{C} 2)$, the question is whether the conditional probability of $\mathrm{H} 1$ (Here is a hand) given $\mathrm{E}$ (My experience is that of a hand held up in front of my face) is higher than the unconditional probability of $\mathrm{H} 2$ (There is a material world). The answer would be obviously no in the everyday context, where there are many experiences other than $\mathrm{E}$ that strongly support the existence of a material world. However, under the assumption we made - that $E$ is the only evidence available that is relevant to the existence of a material world - the answer is not clear. Of the two probabilities to compare, $\operatorname{Pr}(\mathrm{H} 1 \mid \mathrm{E})$ and $\operatorname{Pr}(\mathrm{H} 2)$, the former should be quite high from the assumption that $\mathrm{E}$ confirms $\mathrm{H} 1$ in all four senses, including confirmation-SF. The problem is the latter - it is unclear what probability should be assigned to $\mathrm{H} 2$ in the absence of any evidence. Some may find it highly probable, even in the absence of any evidence, that there is a material world, while others may disagree..$^{29}$ This is an illustration of the general point we made earlier that

${ }^{28}$ For ease of expression, we sometimes refer to $\mathrm{E}$ as an experience. Strictly speaking, of course, $\mathrm{E}$ is a proposition about an experience, not an experience itself.

${ }^{29}$ Some may point out that $(\mathrm{C} 2)$ is satisfied for the purpose of transitivity in confirmation-TSF because $\operatorname{Pr}(\mathrm{H} 2) \leq \mathbf{t}$ from the second antecedent of transitivity in confirmation-TSF, while $\operatorname{Pr}(\mathrm{H} 1 \mid$ E) $>\mathbf{t}$ from the first antecedent of transitivity in confirmation-TSF. However, we are not assuming here that the second antecedent of transitivity in confirmation-TSF holds, precisely for the reason that $\operatorname{Pr}(\mathrm{H} 2)$ is questionable and questioned. The second antecedent of transitivity in the other three 
(C2) is difficult to apply because it requires a heterogeneous comparison. To say which is greater between $\operatorname{Pr}(\mathrm{H} 1 \mid \mathrm{E})$ and $\operatorname{Pr}(\mathrm{H} 2)$, we must make independent quantitative estimates of $\operatorname{Pr}(\mathrm{H} 1 \mid \mathrm{E})$ and $\operatorname{Pr}(\mathrm{H} 2)$. Because of uncertainty of the latter, it is hard to say which is greater: $(\mathrm{C} 2)$ may or may not hold in MOORE.

(C3) is easier to apply than (C2) because it does not require a heterogeneous comparison. Indeed, it is clear in MOORE that (C3) does not hold for the following reason. First, the probability of $\mathrm{E}$ (My experience is that of a hand held up in front of my face) is reduced by the condition $\neg \mathrm{H} 1$ (Here is not a hand). So, $\operatorname{Pr}(\mathrm{E} \mid \neg \mathrm{H} 1)<\operatorname{Pr}(\mathrm{E})$ and this remains true even if we add $\mathrm{H} 2$ (There is a material world) to the condition: Even if there is a material world, the absence of a hand in the vicinity makes the hand-experience less likely. $\operatorname{So}, \operatorname{Pr}(\mathrm{E} \mid \neg \mathrm{H} 1 \wedge \mathrm{H} 2)<\operatorname{Pr}(\mathrm{E})$. It follows by Bayes' Theorem that $\operatorname{Pr}(\neg \mathrm{H} 1 \wedge \mathrm{H} 2 \mid \mathrm{E})<\operatorname{Pr}(\neg \mathrm{H} 1 \wedge \mathrm{H} 2)$. This means that (C3) does not hold in MOORE, and thus E may not confirm-IF, confirm-IF\&SF, or confirm-TSF H2. However, as we also noted earlier, (C3) is stronger than $\left(\mathrm{C}^{\dagger}{ }^{\dagger}\right)$ : In any case in which (C3) holds (and E confirms-IF H1), $\left(\mathrm{C} 1^{\dagger}\right)$ also holds, but there are cases in which $\left(\mathrm{C} 1^{\dagger}\right)$ holds while (C3) does not. So, we still have the hope that $\left(\mathrm{Cl}^{\dagger}\right)$ holds, and hence ( $\left.\mathrm{C} 1\right)$ holds because the other component of (C1) holds trivially in the special case where $\mathrm{H} 1$ entails $\mathrm{H} 2$.

The prospect is brighter here. Shogenji (2003) argues that when E is a perceptual experience and $\mathrm{H} 1$ is its content - as is the case in MOORE- $\mathrm{H} 1$ screens off $\mathrm{E}$ from any proposition $\mathrm{H} 2$ we infer from $\mathrm{H} 1$, where the screening-off condition is understood in the strong sense of $\operatorname{Pr}(\mathrm{H} 2 \mid \mathrm{H} 1)$ $=\operatorname{Pr}(\mathrm{H} 2 \mid \mathrm{H} 1 \wedge \mathrm{E})$ and $\operatorname{Pr}(\mathrm{H} 2 \mid \neg \mathrm{H} 1)=\operatorname{Pr}(\mathrm{H} 2 \mid \neg \mathrm{H} 1 \wedge \mathrm{E})$. For example, once it is given that here is a hand or that here is not a hand, the experience of seeing a hand is no longer relevant to the further inference we make from the existence of a hand or from the non-existence of a hand. There are certain cases where this reasoning fails, but Roche (2012a) shows that in many such cases where the screening-off condition in the strong sense above does not hold, the weaker condition$\operatorname{Pr}(\mathrm{H} 2 \mid \mathrm{H} 1) \leq \operatorname{Pr}(\mathrm{H} 2 \mid \mathrm{H} 1 \wedge \mathrm{E})$ and $\operatorname{Pr}(\mathrm{H} 2 \mid \neg \mathrm{H} 1) \leq \operatorname{Pr}(\mathrm{H} 2 \mid \neg \mathrm{H} 1 \wedge \mathrm{E})$, which we are calling $(\mathrm{C} 1)$ "the Screening-Off Condition" in this paper-still holds. We now examine whether these points hold up in MOORE. Since the first component of (C1) holds trivially in the special case where H1 entails $\mathrm{H} 2$, the question is whether the other component $\left(\mathrm{Cl}^{\dagger}\right) \operatorname{Pr}(\mathrm{H} 2 \mid \neg \mathrm{H} 1) \leq \operatorname{Pr}(\mathrm{H} 2 \mid \neg \mathrm{H} 1 \wedge \mathrm{E})$ holds in MOORE. To find an answer, suppose $\neg \mathrm{H} 1$ (Here is not a hand). This should hardly affect the probability of $\mathrm{H} 2$ (There is a material world): The absence of a particular type of object at a particular location hardly affects the probability that there is a material world. The more important question is how the additional condition E (My experience is that of a hand held up in front of my face) affects the probability of $\mathrm{H} 2$. The reasoning mentioned above is that once it is given that here is no hand, the experience of seeing a hand is no longer relevant to any further inference we make from the non-existence of a hand. However, MOORE is one of those cases where this reasoning does not hold up. The experience of seeing a hand in the absence of a hand calls for an explanation, and one possible explanation is a systematic deception, suggested by the skeptic, that

senses of confirmation is unproblematic: $\mathrm{H} 1$ confirms-IF H2, confirms-SF H2, and confirms$\mathrm{IF} \& \mathrm{SF} \mathrm{H} 2$, from $\operatorname{Pr}(\mathrm{H} 2 \mid \mathrm{H} 1)=1>\mathrm{P}(\mathrm{H} 2)$ and $\operatorname{Pr}(\mathrm{H} 2 \mid \mathrm{H} 1)=1>\mathbf{t}$. 
we are manipulated by a powerful deceiver to think there is a material world, where there is actually none. The troubling part of this possibility is that the additional condition apparently lowers the probability of $\mathrm{H} 2$ (There is a material world): It looks as though $\operatorname{Pr}(\mathrm{H} 2 \mid \neg \mathrm{H} 1)>\operatorname{Pr}(\mathrm{H} 2 \mid$ $\neg \mathrm{H} 1 \wedge \mathrm{E})$ in violation of $\left(\mathrm{C}^{\dagger}\right)$.

This is not the final word on $\left(\mathrm{C}^{\dagger}\right)$ in MOORE, though. We propose to take a different look at $\left(\mathrm{C}^{\dagger}\right)$ in MOORE. First, we re-state $\left(\mathrm{C}^{\dagger}\right) \operatorname{Pr}(\mathrm{H} 2 \mid \neg \mathrm{H} 1) \leq \operatorname{Pr}(\mathrm{H} 2 \mid \neg \mathrm{H} 1 \wedge \mathrm{E})$. By Bayes' Theorem, $\operatorname{Pr}(\mathrm{H} 2 \mid \neg \mathrm{H} 1) \leq \operatorname{Pr}(\mathrm{H} 2 \mid \neg \mathrm{H} 1 \wedge \mathrm{E})$ is equivalent to $\operatorname{Pr}(\mathrm{E} \mid \neg \mathrm{H} 1) \leq \operatorname{Pr}(\mathrm{E} \mid \neg \mathrm{H} 1 \wedge \mathrm{H} 2)$, which is in turn equivalent to $\operatorname{Pr}(\mathrm{E} \mid \neg \mathrm{H} 1 \wedge \neg \mathrm{H} 2) \leq \operatorname{Pr}(\mathrm{E} \mid \neg \mathrm{H} 1 \wedge \mathrm{H} 2)$. Further, since $\mathrm{H} 1$ entails $\mathrm{H} 2$ in MOORE, $\operatorname{Pr}(\mathrm{E} \mid \neg \mathrm{H} 1 \wedge \neg \mathrm{H} 2)=\mathrm{P}(\mathrm{E} \mid \neg \mathrm{H} 2)$, so that $\left(\mathrm{C}^{\dagger}\right)$ amounts to $\operatorname{Pr}(\mathrm{E} \mid \neg \mathrm{H} 2) \leq \operatorname{Pr}(\mathrm{E} \mid \neg \mathrm{H} 1 \wedge$ $\mathrm{H} 2)$. To find out whether $\left(\mathrm{Cl}^{\dagger}\right)$ in this form holds, we estimate which of the two conditions, $\neg \mathrm{H} 2$ on the left side and $\neg \mathrm{H} 1 \wedge \mathrm{H} 2$ on the right side, makes $\mathrm{E}$ more likely. Beginning with the left side, if $\neg \mathrm{H} 2$ (There is not a material world), then $\mathrm{E}$ is true (My experience is that of a hand held up in front of my face) only under extraordinary circumstances, such as deception by the evil demon. Note also that the evil demon must be deceiving us into thinking very specifically that here is a hand. So, $\neg \mathrm{H} 2$ makes E extremely unlikely. In contrast, if $\neg \mathrm{H} 1 \wedge \mathrm{H} 2$ (Here is not a hand, but there is a material world), $\mathrm{E}$ is true (My experience is that of a hand held up in front of my face) not only under deception by the evil demon — which is possible even if there is a material worldbut also under much less unusual circumstances. For example, although here is not a hand, here is

something else that looks like a hand. Because $\mathrm{E}$ is true under more circumstances when there is a material world, we conclude that $\left(\mathrm{C}^{\dagger}\right) \operatorname{Pr}(\mathrm{E} \mid \neg \mathrm{H} 2) \leq \operatorname{Pr}(\mathrm{E} \mid \neg \mathrm{H} 1 \wedge \mathrm{H} 2)$ holds and thus confirmation is transitive in all four senses in MOORE.

There may be an objection to our example that here is not a hand but here is something else that looks like a hand. It may be suggested that Moore's intent is more like:

\section{MOORE*}

\section{$\mathrm{E}^{*}$ : It appears here is something.}

$\mathrm{H} 1 *$ : Here is something.

$\mathrm{H} 2$ : There is a material world.

In MOORE* we can no longer use the example above "although here is not a hand, here is something else that looks like a hand" as a case where $\mathrm{E}^{*}$ is true under the condition of $\neg \mathrm{H} 1^{*} \wedge$ H2. It is nonsensical to say that here is nothing but here is something that looks like something. Fortunately, we can modify the example so that it makes sense in MOORE*. Even if here is nothing, the existence of a material world makes it more likely than otherwise that it appears here is something: For example, here is nothing but there is something elsewhere that appears to be here - it may actually be further away, or you may be looking at a reflection on a mirror, etc. The general point is that where there is a material world, $\mathrm{E}^{*}$ can be true not only by total hallucination but also by mislocation of a material object. Since mislocation of a material object is impossible in 
the absence of a material world, $\mathrm{E}^{*}$ is true under the condition of $\neg \mathrm{H} 2$ only by total hallucination. There is therefore a compelling reason to think that $\left(\mathrm{C}^{\dagger}\right) \operatorname{Pr}\left(\mathrm{E}^{*} \mid \neg \mathrm{H} 2\right) \leq \operatorname{Pr}\left(\mathrm{E}^{*} \mid \neg \mathrm{H} 1^{*} \wedge \mathrm{H} 2\right)$ holds and thus confirmation is transitive in all four senses even in MOORE*.

So, where does all this leave us about Moore's proof? Since H1 entails $\mathrm{H} 2$ and $\left(\mathrm{C}^{\dagger}\right)$ holds, confirmation in all four senses is transitive in MOORE. It is different from the case of a mule disguised as a zebra, where there is a clear breakdown of transitivity in confirmation-IF, confirmation-IF\&SF, and confirmation-TSF. There is, however, a strong sense among many epistemologists that something is not right in MOORE. We suspect the reason for the wariness on the part of many epistemologists is the suspicion that E confirms-TSF H1-E turns H1 sufficiently firm —only if $\mathrm{H} 2$ is already sufficiently firm, thus only if $\mathrm{E}$ does not confirm-TSF $\mathrm{H} 2 .{ }^{30}$ Here is an informal reasoning. E (My experience is that of a hand held up in front of my face) does not confirm-TSF H1 (Here is a hand) against the background of $\neg \mathrm{H} 2$ (There is not a material world). So, when we judge that E confirms-TSF H1, we are tacitly assuming the truth of $\mathrm{H} 2$. This assumption may or may not be justified, but it turns out that MOORE is ineffective either way. If the assumption is justified, then $\operatorname{Pr}(\mathrm{H} 2)>\mathbf{t}$, so that $\mathrm{E}$ does not confirm-TSF H2. ${ }^{31}$ In other words, since $\mathrm{H} 2$ is already sufficiently firm, E does not turn $\mathrm{H} 2$ sufficiently firm-MOORE is therefore ineffective since $\mathrm{E}$ is not needed. If, on the other hand, the assumption is not justified, then $\mathrm{H} 1$ is in doubt because $\mathrm{E}$ does not confirm $\mathrm{H} 1$ without the assumption-MOORE is again ineffective. We note that this reasoning — at least the simple version just described —is not without problems. For example, it is incorrect to say that if $\mathrm{E}$ fails to confirm $\mathrm{H} 1$ against the background of $\neg \mathrm{H} 2$, then $\mathrm{E}$ confirms $\mathrm{H} 1$ only if we assume the truth of $\mathrm{H} 2$. It is possible that $\operatorname{Pr}(\mathrm{H} 1 \mid \mathrm{E})=$ $\operatorname{Pr}(\mathrm{H} 1 \mid \mathrm{H} 2 \wedge \mathrm{E}) \operatorname{Pr}(\mathrm{H} 2 \mid \mathrm{E})+\operatorname{Pr}(\mathrm{H} 1 \mid \neg \mathrm{H} 2 \wedge \mathrm{E}) \operatorname{Pr}(\neg \mathrm{H} 2 \mid \mathrm{E})>\mathbf{t}$ even if $\operatorname{Pr}(\mathrm{H} 1 \mid \mathrm{E} \wedge \neg \mathrm{H} 2) \leq \mathbf{t}$. Our only point here is that there is a promising line of reasoning that casts doubt on the effectiveness of MOORE, and the reasoning is consistent with the transitivity of confirmation in all four senses in MOORE.

\section{Appendix A: Proof of Theorem 2}

Let (X) be any of (C1)-(C3). Suppose (a) E confirms-IF\&SF H1, so (a1) $\operatorname{Pr}(\mathrm{H} 1 \mid \mathrm{E})>\operatorname{Pr}(\mathrm{H} 1)$ and (a2) $\operatorname{Pr}(\mathrm{H} 1 \mid$ E) $>$ t. Suppose (b) H1 confirms-IF\&SF H2, therefore (b1) $\operatorname{Pr}(\mathrm{H} 2 \mid \mathrm{H} 1)>\operatorname{Pr}(\mathrm{H} 2)$ and (b2) $\operatorname{Pr}(\mathrm{H} 2 \mid \mathrm{H} 1)>$ t. Suppose (c) H1 entails H2 and (d) (X) holds. By (a1), (b1), (c), (d), and Theorem 1, it follows that $\operatorname{Pr}(\mathrm{H} 2 \mid \mathrm{E})>\operatorname{Pr}(\mathrm{H} 2)$. By (c) and the theorem that if $\mathrm{H} 1$ entails $\mathrm{H} 2$, then

\footnotetext{
${ }^{30}$ Since confirmation-TSF is transitive in MOORE, it follows that H1 does not confirm-TSF $\mathrm{H} 2$. As we noted in footnote 29 we are not making the assumption that H1 confirms-TSF H2. Our claim of transitivity in confirmation-TSF in MOORE is of the form: If E confirms-TSF H1 and H1 in turn confirms-TSF H2, then E confirms-TSF H2.

${ }^{31}$ We can state the point more simply: $\operatorname{If} \operatorname{Pr}(\mathrm{H} 1 \mid \mathrm{E})>\mathbf{t}$, then $\operatorname{Pr}(\mathrm{H} 2)>\mathbf{t}$. Note that this does not imply the failure of $(\mathrm{C} 2) \operatorname{Pr}(\mathrm{H} 2)<\operatorname{Pr}(\mathrm{H} 1 \mid \mathrm{E})$. (C2) can be true while $\operatorname{Pr}(\mathrm{H} 1 \mid \mathrm{E})>\mathbf{t}$ and $\operatorname{Pr}(\mathrm{H} 2)$ $>\mathbf{t}$, and thus the conditional is also true.
} 
$\operatorname{Pr}(\mathrm{H} 2 \mid \mathrm{E}) \geq \operatorname{Pr}(\mathrm{H} 1 \mid \mathrm{E})$, it follows that $\operatorname{Pr}(\mathrm{H} 2 \mid \mathrm{E}) \geq \operatorname{Pr}(\mathrm{H} 1 \mid \mathrm{E})$. By (a2), it then follows that $\operatorname{Pr}(\mathrm{H} 2 \mid$ E) $>$ t. So $\operatorname{Pr}(\mathrm{H} 2 \mid$ E $)>\operatorname{Pr}(\mathrm{H} 2)$ and $\operatorname{Pr}(\mathrm{H} 2 \mid$ E $)>$ t. So E confirms-IF\&SF H2.

\section{Appendix B: Proof of Theorem 3}

Let (X) be any of (C1)-(C3). Suppose (a) E confirms-TSF H1, so (a1) $\operatorname{Pr}(\mathrm{H} 1 \mid \mathrm{E})>\operatorname{Pr}(\mathrm{H} 1)$, (a2) $\operatorname{Pr}(\mathrm{H} 1 \mid \mathrm{E})>\mathbf{t}$, and (a3) $\operatorname{Pr}(\mathrm{H} 1) \leq \mathbf{t}$. Suppose (b) H1 confirms-TSF H2, therefore (b1) $\operatorname{Pr}(\mathrm{H} 2 \mid \mathrm{H} 1)>$ $\operatorname{Pr}(\mathrm{H} 2)$, (b2) $\operatorname{Pr}(\mathrm{H} 2 \mid \mathrm{H} 1)>\mathbf{t}$, and (b3) $\operatorname{Pr}(\mathrm{H} 2) \leq \mathbf{t}$. Suppose (c) H1 entails $\mathrm{H} 2$ and (d) (X) holds. By (a1), (a2), (b1), (b2), (c), (d), and Theorem 2, it follows that $\operatorname{Pr}(\mathrm{H} 2 \mid \mathrm{E})>\operatorname{Pr}(\mathrm{H} 2)$ and $\operatorname{Pr}(\mathrm{H} 2 \mid \mathrm{E})>$ t. $\mathrm{By}(\mathrm{b} 3), \operatorname{Pr}(\mathrm{H} 2) \leq \mathbf{t}$. Hence $\operatorname{Pr}(\mathrm{H} 2 \mid \mathrm{E})>\operatorname{Pr}(\mathrm{H} 2), \operatorname{Pr}(\mathrm{H} 2 \mid \mathrm{E})>\mathbf{t}$, and $\operatorname{Pr}(\mathrm{H} 2) \leq \mathbf{t}$. Hence $\mathrm{E}$ confirms-TSF H2.

\section{Appendix C: Proof of Theorem 5B}

Suppose a card is randomly drawn from a standard deck of cards. Let E be the claim "The card drawn is a Heart", $\mathrm{H} 1$ be the claim "The card drawn is a Red", and H2 be the claim "The card drawn is a Diamond". Then, E confirms-IF H1, since $\operatorname{Pr}(\mathrm{H} 1 \mid \mathrm{E})=1>\operatorname{Pr}(\mathrm{H} 1)=1 / 2$, and H1 confirms-IF H2, given that $\operatorname{Pr}(\mathrm{H} 2 \mid \mathrm{H} 1)=1 / 2>\operatorname{Pr}(\mathrm{H} 2)=1 / 4$, and both (C2) and (C3) hold, since $\operatorname{Pr}(\mathrm{H} 2)=1 / 4<\operatorname{Pr}(\mathrm{H} 1 \mid \mathrm{E})=1$ and $\operatorname{Pr}(\mathrm{H} 2 \wedge \neg \mathrm{H} 1 \mid \mathrm{E})=0=\operatorname{Pr}(\mathrm{H} 2 \wedge \neg \mathrm{H} 1)$. But $\mathrm{E}$ does not confirmIF $\mathrm{H} 2 ; \operatorname{Pr}(\mathrm{H} 2 \mid \mathrm{E})=0<\operatorname{Pr}(\mathrm{H} 2)=1 / 4$.

\section{Appendix D: Proof of Theorem 6}

Consider the following schema, to be referred to (for lack of a better name) as "Schema", where $\beta$ $\in \mathbb{R}^{+}, \beta \geq 1$, and $\tau=1+(2 / 10)^{\beta}+(1 / 10)^{\beta}+(9 / 10)^{\beta}+(1 / 10)^{\beta}+(1 / 10)^{\beta}+10^{\beta}$ :

\section{Schema}

\begin{tabular}{lllllllll}
\hline $\mathrm{E}$ & $\mathrm{H} 1$ & $\mathrm{H} 2$ & $\mathrm{Pr}$ & & $\mathrm{E}$ & $\mathrm{H} 1$ & $\mathrm{H} 2$ & $\mathrm{Pr}$ \\
\hline $\mathrm{N}$ & $\mathrm{T}$ & $\mathrm{T}$ & $1 / \tau$ & & $\mathrm{F}$ & $\mathrm{T}$ & $\mathrm{T}$ & $(1 / 10)^{\beta} / \tau$ \\
$\mathrm{T}$ & $\mathrm{T}$ & $\mathrm{F}$ & $(2 / 10)^{\beta} / \tau$ & & $\mathrm{F}$ & $\mathrm{T}$ & $\mathrm{F}$ & $(1 / 10)^{\beta} / \tau$ \\
$\mathrm{T}$ & $\mathrm{F}$ & $\mathrm{T}$ & $(1 / 10)^{\beta} / \tau$ & & $\mathrm{F}$ & $\mathrm{F}$ & $\mathrm{T}$ & 0 \\
$\mathrm{~T}$ & $\mathrm{~F}$ & $\mathrm{~F}$ & $(9 / 10)^{\beta} / \tau$ & & $\mathrm{F}$ & $\mathrm{F}$ & $\mathrm{F}$ & $10^{\beta} / \tau$ \\
\hline
\end{tabular}

On each instance of Schema, it follows that: 
(1) $\operatorname{Pr}(\mathrm{H} 2 \mid \mathrm{E} \wedge \mathrm{H} 1)-\operatorname{Pr}(\mathrm{H} 2 \mid \mathrm{H} 1)=\frac{1}{1+\left(\frac{2}{10}\right)^{\beta}}-\frac{1+\left(\frac{1}{10}\right)^{\beta}}{1+\left(\frac{2}{10}\right)^{\beta}+\left(\frac{1}{10}\right)^{\beta}+\left(\frac{1}{10}\right)^{\beta}}>0$;

(2) $\operatorname{Pr}(\mathrm{H} 2 \mid \mathrm{E} \wedge \neg \mathrm{H} 1)-\operatorname{Pr}(\mathrm{H} 2 \mid \neg \mathrm{H} 1)=\frac{\left(\frac{1}{10}\right)^{\beta}}{\left(\frac{1}{10}\right)^{\beta}+\left(\frac{9}{10}\right)^{\beta}}-\frac{\left(\frac{1}{10}\right)^{\beta}}{\left(\frac{1}{10}\right)^{\beta}+\left(\frac{9}{10}\right)^{\beta}+10^{\beta}}>0$;

(3) $\operatorname{Pr}(\mathrm{H} 1 \mid \mathrm{E})-\operatorname{Pr}(\mathrm{H} 2)=\frac{1+\left(\frac{2}{10}\right)^{\beta}}{1+\left(\frac{2}{10}\right)^{\beta}+\left(\frac{1}{10}\right)^{\beta}+\left(\frac{9}{10}\right)^{\beta}}$

$$
-\frac{1+\left(\frac{1}{10}\right)^{\beta}+\left(\frac{1}{10}\right)^{\beta}}{1+\left(\frac{2}{10}\right)^{\beta}+\left(\frac{1}{10}\right)^{\beta}+\left(\frac{9}{10}\right)^{\beta}+\left(\frac{1}{10}\right)^{\beta}+\left(\frac{1}{10}\right)^{\beta}+10^{\beta}}>0
$$

(4) $\operatorname{Pr}(\mathrm{H} 2 \wedge \neg \mathrm{H} 1 \mid \mathrm{E})-\operatorname{Pr}(\mathrm{H} 2 \wedge \neg \mathrm{H} 1)=\frac{\left(\frac{1}{10}\right)^{\beta}}{1+\left(\frac{2}{10}\right)^{\beta}+\left(\frac{1}{10}\right)^{\beta}+\left(\frac{9}{10}\right)^{\beta}}$

$$
-\frac{\left(\frac{1}{10}\right)^{\beta}}{1+\left(\frac{2}{10}\right)^{\beta}+\left(\frac{1}{10}\right)^{\beta}+\left(\frac{9}{10}\right)^{\beta}+\left(\frac{1}{10}\right)^{\beta}+\left(\frac{1}{10}\right)^{\beta}+10^{\beta}}
$$

$>0$.

By (1) and (2) it follows that (C1) holds. By (3) it follows that (C2) holds. By (4) it follows that (C3) holds.

The aim is to show that regardless of the value specified for $\boldsymbol{t}$ there are instances of Schema on which E confirms-IF\&SF H1, H1 confirms-IF\&SF H2, and yet, though E confirms-IF H2, E does not confirm-IF\&SF $\mathrm{H} 2$ because $\operatorname{Pr}(\mathrm{H} 2 \mid \mathrm{E}) \ngtr \mathbf{t}$.

First, observe that each of $\operatorname{Pr}(\mathrm{H} 1 \mid \mathrm{E})$ and $\operatorname{Pr}(\mathrm{H} 2 \mid \mathrm{H} 1)$ approaches 1 as $\beta$ tends to $\infty$ :

(5) $\lim _{\beta \rightarrow \infty} \frac{1+\left(\frac{2}{10}\right)^{\beta}}{1+\left(\frac{2}{10}\right)^{\beta}+\left(\frac{1}{10}\right)^{\beta}+\left(\frac{9}{10}\right)^{\beta}}=1$;

(6) $\lim _{\beta \rightarrow \infty} \frac{1+\left(\frac{1}{10}\right)^{\beta}}{1+\left(\frac{2}{10}\right)^{\beta}+\left(\frac{1}{10}\right)^{\beta}+\left(\frac{1}{10}\right)^{\beta}}=1$. 
So, regardless of the value specified for $\mathbf{t}$ there is a value for $\beta$ such that $\operatorname{Pr}(\mathrm{H} 1 \mid \mathrm{E})>\mathbf{t}$ and $\operatorname{Pr}(\mathrm{H} 2 \mid$ H1) $>\mathbf{t}$.

The same is true of $\operatorname{Pr}(\mathrm{H} 2 \mid \mathrm{E})$, since $\operatorname{Pr}(\mathrm{H} 2 \mid \mathrm{E})$, like each of $\operatorname{Pr}(\mathrm{H} 1 \mid \mathrm{E})$ and $\operatorname{Pr}(\mathrm{H} 2 \mid \mathrm{H} 1)$, approaches 1 as $\beta$ tends to $\infty$ :

(7) $\lim _{\beta \rightarrow \infty} \frac{1+\left(\frac{1}{10}\right)^{\beta}}{1+\left(\frac{2}{10}\right)^{\beta}+\left(\frac{1}{10}\right)^{\beta}+\left(\frac{9}{10}\right)^{\beta}}=1$.

But, crucially, the following inequalities hold:

(8) $\operatorname{Pr}(\mathrm{H} 1 \mid \mathrm{E})=\frac{1+\left(\frac{2}{10}\right)^{\beta}}{1+\left(\frac{2}{10}\right)^{\beta}+\left(\frac{1}{10}\right)^{\beta}+\left(\frac{9}{10}\right)^{\beta}}>\frac{1+\left(\frac{1}{10}\right)^{\beta}}{1+\left(\frac{2}{10}\right)^{\beta}+\left(\frac{1}{10}\right)^{\beta}+\left(\frac{9}{10}\right)^{\beta}}=\operatorname{Pr}(\mathrm{H} 2 \mid \mathrm{E})$;

(9) $\operatorname{Pr}(\mathrm{H} 2 \mid \mathrm{H} 1)=\frac{1+\left(\frac{1}{10}\right)^{\beta}}{1+\left(\frac{2}{10}\right)^{\beta}+\left(\frac{1}{10}\right)^{\beta}+\left(\frac{1}{10}\right)^{\beta}}>\frac{1+\left(\frac{1}{10}\right)^{\beta}}{1+\left(\frac{2}{10}\right)^{\beta}+\left(\frac{1}{10}\right)^{\beta}+\left(\frac{9}{10}\right)^{\beta}}=\operatorname{Pr}(\mathrm{H} 2 \mid \mathrm{E})>0$.

Next, consider the inequalities:

(10) $\operatorname{Pr}(\mathrm{H} 1 \mid \mathrm{E})-\operatorname{Pr}(\mathrm{H} 1)>0$;

(11) $\operatorname{Pr}(\mathrm{H} 2 \mid \mathrm{H} 1)-\operatorname{Pr}(\mathrm{H} 2)>0$.

We noted above that each of $\operatorname{Pr}(\mathrm{H} 1 \mid \mathrm{E})$ and $\operatorname{Pr}(\mathrm{H} 2 \mid \mathrm{H} 1)$ approaches 1 as $\beta$ tends to $\infty$. This is not true of $\operatorname{Pr}(\mathrm{H} 1)$ and $\operatorname{Pr}(\mathrm{H} 2)$ - quite the opposite in fact. Each of $\operatorname{Pr}(\mathrm{H} 1)$ and $\operatorname{Pr}(\mathrm{H} 2)$ approaches 0 as $\beta$ tends to $\infty$ :

$$
\begin{aligned}
& \text { (12) } \lim _{\beta \rightarrow \infty} \frac{1+\left(\frac{2}{10}\right)^{\beta}+\left(\frac{1}{10}\right)^{\beta}+\left(\frac{1}{10}\right)^{\beta}}{1+\left(\frac{2}{10}\right)^{\beta}+\left(\frac{1}{10}\right)^{\beta}+\left(\frac{9}{10}\right)^{\beta}+\left(\frac{1}{10}\right)^{\beta}+\left(\frac{1}{10}\right)^{\beta}+10^{\beta}}=0 \\
& \text { (13) } \lim _{\beta \rightarrow \infty} \frac{1+\left(\frac{1}{10}\right)^{\beta}+\left(\frac{1}{10}\right)^{\beta}}{1+\left(\frac{2}{10}\right)^{\beta}+\left(\frac{1}{10}\right)^{\beta}+\left(\frac{9}{10}\right)^{\beta}+\left(\frac{1}{10}\right)^{\beta}+\left(\frac{1}{10}\right)^{\beta}+10^{\beta}}=0 .
\end{aligned}
$$


With $\beta=1, \operatorname{Pr}(\mathrm{H} 1 \mid \mathrm{E})=6 / 11>\operatorname{Pr}(\mathrm{H} 1)=7 / 62$ and $\operatorname{Pr}(\mathrm{H} 2 \mid \mathrm{H} 1)=11 / 14>\operatorname{Pr}(\mathrm{H} 2)=3 / 31$. So, given (5), (6), (12), and (13), and with $\beta \geq 1$, it follows that (10) and (11) hold. ${ }^{32}$

The argument now runs as follows. Take $\beta=1$. Then $\operatorname{Pr}(\mathrm{H} 1 \mid \mathrm{E})=6 / 11>\operatorname{Pr}(\mathrm{H} 1)=7 / 62$,

$\operatorname{Pr}(\mathrm{H} 2 \mid \mathrm{H} 1)=11 / 14>\operatorname{Pr}(\mathrm{H} 2)=3 / 31$, and $\operatorname{Pr}(\mathrm{H} 2 \mid \mathrm{E})=1 / 2$. If $6 / 11>\mathbf{t}>.5$, we have an instance of Schema on which E confirms-IF\&SF H1, H1 confirms-IF\&SF H2, and yet, though E confirms-IF $\mathrm{H} 2$, E does not confirm-IF\&SF H2 because $\operatorname{Pr}(\mathrm{H} 2 \mid \mathrm{E}) \ngtr \mathbf{t}$. If, instead, $\mathbf{t} \geq 6 / 11$, then let the value of $\beta$ increase until $\operatorname{Pr}(\mathrm{H} 1 \mid \mathrm{E})>\mathbf{t}$ and $\operatorname{Pr}(\mathrm{H} 2 \mid \mathrm{H} 1)>\mathbf{t}$ but $\operatorname{Pr}(\mathrm{H} 2 \mid \mathrm{E}) \ngtr \mathbf{t}$; that there is such a value for $\beta$ is guaranteed by (5), (6), (8), and (9). It will still be the case that $\operatorname{Pr}(\mathrm{H} 1 \mid \mathrm{E})>\operatorname{Pr}(\mathrm{H} 1)$ and $\operatorname{Pr}(\mathrm{H} 2 \mid \mathrm{H} 1)>\operatorname{Pr}(\mathrm{H} 2)$; this follows from (10) and (11). The resulting distribution will be an instance of Schema on which E confirms-IF\&SF H1, H1 confirms-IF\&SF H2, and E confirms-IF $\mathrm{H} 2$ but does not confirm-IF\&SF $\mathrm{H} 2$ given that $\operatorname{Pr}(\mathrm{H} 2 \mid \mathrm{E}) \ngtr \mathbf{t}$.

The result is that none of $(\mathrm{C} 1),(\mathrm{C} 2)$, and $(\mathrm{C} 3)$ is a condition for transitivity in confirmationIF\&SF regardless of the value specified for $\mathbf{t}^{33}$

\section{Appendix E: Proof of Theorem 7}

Consider Schema, and take $\beta=1$. Then, as noted above, $\operatorname{Pr}(\mathrm{H} 1 \mid \mathrm{E})=6 / 11>\operatorname{Pr}(\mathrm{H} 1)=7 / 62, \operatorname{Pr}(\mathrm{H} 2$ $\mid \mathrm{H} 1)=11 / 14>\operatorname{Pr}(\mathrm{H} 2)=3 / 31$, and $\operatorname{Pr}(\mathrm{H} 2 \mid \mathrm{E})=1 / 2$. If $6 / 11>\mathbf{t}>.5$, we have an instance of Schema on which E confirms-TSF H1, H1 confirms-TSF H2, and yet, though E confirms-IF H2, E does not confirm-TSF $\mathrm{H} 2$ because $\operatorname{Pr}(\mathrm{H} 2 \mid \mathrm{E}) \ngtr \mathbf{t}$. If $\mathbf{t} \geq 6 / 11$, then, as explained above, let the value of $\beta$ increase until $\operatorname{Pr}(\mathrm{H} 1 \mid \mathrm{E})>\mathbf{t}$ and $\operatorname{Pr}(\mathrm{H} 2 \mid \mathrm{H} 1)>\mathbf{t}$ but $\operatorname{Pr}(\mathrm{H} 2 \mid \mathrm{E}) \ngtr \mathbf{t}$. Given (10) and (11), it will still be the case that $\operatorname{Pr}(\mathrm{H} 1 \mid \mathrm{E})>\operatorname{Pr}(\mathrm{H} 1)$ and $\operatorname{Pr}(\mathrm{H} 2 \mid \mathrm{H} 1)>\operatorname{Pr}(\mathrm{H} 2)$. Given (12) and (13), it will still be the case that $\operatorname{Pr}(\mathrm{H} 1) \leq \mathbf{t}$ and $\operatorname{Pr}(\mathrm{H} 2) \leq \mathbf{t}$. The resulting distribution will thus be an instance of Schema on which E confirms-TSF H1, H1 confirms-TSF H2, but, since $\operatorname{Pr}(\mathrm{H} 2 \mid \mathrm{E}) \ngtr \mathbf{t}$, $\mathrm{E}$ does not confirm-TSF H2. Therefore, regardless of the value specified for $\mathbf{t}$, none of $(\mathrm{C} 1)$, (C2), and (C3) is a condition for transitivity in confirmation-TSF.

\section{Appendix F: Proof of Theorem 8}

\footnotetext{
${ }^{32}$ Bear in mind here and throughout the remainder of the argument that $\operatorname{Pr}(\mathrm{H} 1 \mid \mathrm{E})$ and $\operatorname{Pr}(\mathrm{H} 2 \mid$ $\mathrm{H} 1)$ are continuous montonically increasing functions of $\beta$, and that $\operatorname{Pr}(\mathrm{H} 1)$ and $\operatorname{Pr}(\mathrm{H} 2)$ are continuous montonically decreasing functions of $\beta$.

${ }^{33}$ See Roche (2012b) for a similar argument for the claim that regardless of the value specified for $\mathbf{t}$ the following condition is not a condition for transitivity in confirmation-IF\&SF: $\operatorname{Pr}(\mathrm{H} 2 \mid \mathrm{E} \wedge \mathrm{H} 1)>\operatorname{Pr}(\mathrm{H} 2 \mid \mathrm{H} 1)$ and $\operatorname{Pr}(\mathrm{H} 2 \mid \mathrm{E} \wedge \neg \mathrm{H} 1)>\operatorname{Pr}(\mathrm{H} 2 \mid \neg \mathrm{H} 1)$. Note that this condition is stronger than $(\mathrm{C} 1)$ and neither stronger nor weaker than $\left(\mathrm{C} 1^{*}\right)$, and that, like $(\mathrm{C} 1)$ and $\left(\mathrm{C} 1^{*}\right)$, it is a condition for transitivity in confirmation-IF.
} 
We showed above in the proof of Theorem 6 that regardless of the value specified for $\mathbf{t}$ there is an instance of Schema on which E confirms-IF\&SF H1, H1 confirms-IF\&SF H2, and E confirms-IF $\mathrm{H} 2$ but does not confirm-IF\&SF H2 given that $\operatorname{Pr}(H 2 \mid E) \ngtr t$. It follows immediately that regardless of the value specified for $\mathbf{t}$ there is an instance of Schema on which E confirms-SF H1, $\mathrm{H} 1$ confirms-SF H2, and E confirms-IF H2 but does not confirm-SF H2 because $\operatorname{Pr}(\mathrm{H} 2 \mid \mathrm{E}) \ngtr \mathbf{t}$. None of $(\mathrm{C} 1),(\mathrm{C} 2)$, and $(\mathrm{C} 3)$, therefore, is a condition for transitivity in confirmation-SF regardless of the value specified for $\mathbf{t}$.

\section{Acknowledgments}

We thank an anonymous reviewer for very helpful comments on a prior version of the paper.

\section{References}

Beebee, H. (2001). Transfer of warrant, begging the question, and semantic externalism. Philosophical Quarterly, 51, 356-374.

Brown, J. (2003). The reductio argument and transmission of warrant. In S. Nuccetelli (Ed.), New essays on semantic externalism and self-knowledge (pp. 117-130). Cambridge, Mass.: MIT Press.

Brown, J. (2004). Wright on transmission failure. Analysis, 64, 57-67.

Carnap, R. (1962). Logical foundations of probability (2nd ed.). Chicago: University of Chicago Press.

Chandler, J. (2010). The transmission of support: A Bayesian re-analysis. Synthese, 176, 333-343.

Cling, A. (2002). Justification-affording circular arguments. Philosophical Studies, 111, 251-275.

Cohen, S. (2005). Why basic knowledge is easy knowledge. Philosophy and Phenomenological Research, 70, 417-430.

Coliva, A. (2011). Varieties of failure (of warrant transmission: what else?!). Synthese. To appear. doi: 10.1007/s11229-011-0006-6.

Davies, M. (1998). Externalism, architecturalism, and epistemic warrant. In C. Wright, B. Smith, and C. Macdonald (Eds.), Knowing our own minds (pp. 321-361). Oxford: Oxford University Press.

Davies, M. (2000). Externalism and armchair knowledge. In P. Boghossian and C. Peacocke (Eds.), New essays on the a priori (pp. 384-414). Oxford: Oxford University Press.

Davies, M. (2003). The problem of armchair knowledge. In S. Nuccetelli (Ed.), New essays on semantic externalism and self-knowledge (pp. 23-55). Cambridge, Mass.: MIT Press.

Davies, M. (2004). Epistemic entitlement, warrant transmission and easy knowledge. Proceedings of the Aristotelian Society, Supplementary Volumes, 78, 213-245. 
Confirmation, Transitivity, and Moore: The Screening-Off Approach

Douven, I. (2011). Further results on the intransitivity of evidential support. Review of Symbolic Logic, 4, 487-497.

Dretske, F. (1970). Epistemic operators. Journal of Philosophy, 67, 1007-1023.

Dretske, F. (2005a). The case against closure. In M. Steup and E. Sosa (Eds.), Contemporary debates in epistemology (pp. 13-26). Malden: Blackwell.

Dretske, F. (2005b). Reply to Hawthorne. In M. Steup and E. Sosa (Eds.), Contemporary debates in epistemology (pp. 43-46). Malden: Blackwell.

Ebert, P. (2005). Transmission of warrant-failure and the notion of epistemic analyticity. Australasian Journal of Philosophy, 83, 505-521.

Hale, B. (2000). Transmission and closure. Philosophical Issues, 10, 172-190.

Hawthorne, J. (2004). Knowledge and lotteries. Oxford: Clarendon.

Hawthorne, J. (2005). The case for closure. In M. Steup and E. Sosa (Eds.), Contemporary debates in epistemology (pp. 26-43). Malden: Blackwell.

Hempel, C. (1965). Studies in the logic of confirmation. In C. Hempel, Aspects of scientific explanation and other essays in the philosophy of science (pp. 3-46). New York: Free Press.

Kotzen, M. (2012). Dragging and confirming. Philosophical Review, 121, 55-93.

Kukla, A. (1998). Studies in scientific realism. Oxford: Oxford University Press.

McKinsey, M. (2003). Transmission of warrant and closure of apriority. In S. Nuccetelli (Ed.), New essays on semantic externalism and self-knowledge (pp. 97-115). Cambridge, Mass.: MIT Press.

McLaughlin, B. (2003). McKinsey's challenge, warrant transmission, and skepticism. In S. Nuccetelli (Ed.), New essays on semantic externalism and self-knowledge (pp. 79-96). Cambridge, Mass.: MIT Press.

Milne, P. (2000). Is there a logic of confirmation transfer? Erkenntnis, 53, 309-335.

Moretti, L. (2002). For a Bayesian account of indirect confirmation. Dialectica, 56, 153-173.

Moretti, L. (2012). Wright, Okasha and Chandler on transmission failure. Synthese, 184, 217-234.

Moretti, L., and Piazza, T. (2011). When warrant transmits and when it doesn't: Towards a general framework. Synthese. To appear. doi: 10.1007/s11229-011-0018-2.

Neta, R. (2007). Fixing the transmission: The new Mooreans. In S. Nuccetelli and G. Seay (Eds.), Themes from G. E. Moore: New essays in epistemology and ethics (pp. 62-83). Oxford: Oxford University Press.

Okasha, S. (1999). Epistemic justification and deductive closure. Crítica, 31, 37-51.

Okasha, S. (2004). Wright on the transmission of support: A Bayesian analysis. Analysis, 64, 139146.

Peacocke, C. (2004). The realm of reason. Oxford: Oxford University Press.

Pryor, J. (2004). What's wrong with Moore's argument? Philosophical Issues, 14, 349-378.

Pynn, G. (2011). The Bayesian explanation of transmission failure. Synthese. To appear. doi: 10.1007/s11229-011-9890-z.

Roche, W. (2012a). A weaker condition for transitivity in probabilistic support. European Journal for Philosophy of Science, 2, 111-118. 
Roche, W. (2012b). Transitivity and intransitivity in evidential support: Some further results. Review of Symbolic Logic, 5, 259-268.

Sainsbury, R. M. (2000). Warrant-transmission, defeaters and disquotation. Philosophical Issues, 10, 191-200.

Schiffer, S. (2004). Skepticism and the vagaries of justified belief. Philosophical Studies, 119, 161-184.

Shogenji, T. (2003). A condition for transitivity in probabilistic support. British Journal for the Philosophy of Science, 54, 613-616.

Shogenji, T. (2012). The degree of epistemic justification and the conjunction fallacy. Synthese, $184,29-48$.

Silins, N. (2005). Transmission failure failure. Philosophical Studies, 126, 71-102.

Silins, N. (2007). Basic justification and the Moorean response to the skeptic. In T. Gendler and J. Hawthorne (Eds.), Oxford Studies in Epistemology: Volume 2 (pp. 108-140). Oxford: Oxford University Press.

Smith, M. (2009). Transmission failure explained. Philosophy and Phenomenological Research, $79,164-189$.

Suarez, A. (2000). On Wright's diagnosis of McKinsey's argument. Philosophical Issues, 10, 164171.

Tucker, C. (2010a). When transmission fails. Philosophical Review, 119, 497-529.

Tucker, C. (2010b). Transmission and transmission failure in epistemology. In J. Fieser and B. Dowden (Eds.), Internet Encyclopedia of Philosophy (published October 2010). http://www.iep.utm.edu/transmis/. Accessed 3 Feb 2012.

White, R. (2006). Problems for dogmatism. Philosophical Studies, 131, 525-557.

Wright, C. (1985). Facts and certainty. Proceedings of the British Academy, 71, 429-472.

Wright, C. (2000a). Cogency and question-begging: Some reflections on McKinsey's paradox and Putnam's proof. Philosophical Issues, 10, 140-163.

Wright, C. (2000b). Replies. Philosophical Issues, 10, 201-219.

Wright, C. (2002). (Anti-)sceptics simple and subtle: G. E. Moore and John McDowell. Philosophy and Phenomenological Research, 65, 330-348.

Wright, C. (2003). Some reflections on the acquisition of warrant by inference. In S. Nuccetelli (Ed.), New essays on semantic externalism and self-knowledge (pp. 57-77). Cambridge, Mass.: MIT Press.

Wright, C. (2004). Warrant for nothing (and foundations for free)? Proceedings of the Aristotelian Society, Supplementary Volumes, 78, 167-212.

Wright, C. (2007). The perils of dogmatism. In S. Nuccetelli and G. Seay (Eds.), Themes from G. E. Moore: New essays in epistemology and ethics (pp. 25-48). Oxford: Oxford University Press.

Wright. C. (2011). McKinsey one more time. In A. Hatzimoysis (Ed.), Self-knowledge (pp. 80104). Oxford: Oxford University Press. 